\title{
Current Advances in Cerebral Malaria Associated Encephalopathy
}

\author{
Mingli Liu, Shanchun Guo, Monica Battle and Jonathan K. Stiles \\ Microbiology, Biochemistry \& Immunology, \\ Morehouse School of Medicine, \\ Atlanta, GA \\ USA
}

\section{Introduction}

Malaria (Plasmodium falciparum) infects 200 to 300 million people globally and kills 900,000 (mostly children) every year. Severe malaria-related pathogeneses impacts a broad spectrum of host system and multiple organs (Zhu, Wu et al. 2009). Up to $20 \%$ of fatal cases are due to cerebral malaria (CM) and other severe forms of malaria such as severe malaria anemia (SMA). The precise mechanisms responsible for fatal CM-induced brain damage are unclear. To date, two main hypotheses have been proposed for human cerebral malaria. The first is the mechanical hypothesis, which proposes that infected or parasitized red blood cells (iRBC, or $\mathrm{pRBC}$ ) bind to endothelial cells (EC), thus obstructing blood flow in micro capillaries leading to low tissue perfusion, compromised oxygenation and tissue damage. The second is the immunopathological hypothesis which proposes that hyper-inflammatory responses responsible for eliminating $P$. falciparum parasite cause edema, dysfunction in blood brain barrier (BBB), and organ failure and death.

Current anti-malaria drugs, such as quinine and artemisinin derivatives can effectively clear the parasites in blood, however a significant segment of severe malaria patients including $\mathrm{CM}$ patients still die or develop severe sequelae regardless of treatment (Taoufiq, Gay et al. 2008; Balachandar and Katyal 2010). Therefore important questions remain to be answered concerning the mechanism/(s) governing CM pathogenesis and appropriate therapies. The existing anti-malaria therapies are not sufficient partly due to drug resistance and various side effects, but beyond that these treatments mainly focus on the clearance of parasite, a direct antiplasmodial strategy, and are unable to prevent secondary changes such as encephalopathy resulting from parasite derived factors. The molecular mechanisms involved in malaria pathogenesis are highly complex and multifactorial. Recent studies have demonstrated that many pathological changes result from malaria-induced secondary effects involving various signaling molecules of the host (Armah, Wilson et al. 2007; Pamplona, Ferreira et al. 2007; Pamplona, Hanscheid et al. 2009). A better understanding of malaria host-parasite interactions will facilitate the development of novel strategies for intervention. 


\section{Pathological abnormalities associated with $\mathrm{CM}$}

\subsection{Histopathologic hallmarks of the CM}

The histopathologic hallmark of $\mathrm{CM}$ is sequestration of infected red blood cells in the microcirculation of the brain and retina (White 2011). A study performed in South Asia to quantitatively analyze the microvascular sequestration of $P$. falciparum in human brain demonstrated that sequestration occurs in all patients with falciparum malaria and is a consistent characteristic of severe malaria (Silamut, Phu et al. 1999). Fibrin thrombi and perivascular ring hemorrhages are also frequently found intravascular and extravascular. Diffuse petechial hemorrhages are seen in the cerebrum and cerebellum (Patankar, Karnad et al. 2002). Red blood cells (RBCs) around capillaries with hemorrhages are usually noninfected, because parasitized RBCs (pRBCs) are adherent to the endothelial cells in the vessel walls and are unable to freely bleed into the parenchyma (sequestration theory) (White 2011). Patches of necrosis are present around vessels with thrombi, with or without hemorrhages. Inflammation in the parenchyma of the brain or retina is not significant. Antimalaria therapy could effectively eliminate parasites from the brains, but such interventions cannot always reverse malaria-induced primary or secondary pathological processes in severely diseased individuals. Circulating pRBCs will sequester as they mature (schizonts and trophozoites) (Silamut, Phu et al. 1999; Rogerson, Grau et al. 2004), but it is unclear what determines adherence to sites where severe pathology is common in the brain compared to sites where consequences appear minor such as in gastrointestinal tract and skin (Rogerson, Grau et al. 2004). Histopathological studies from animal models have also indicated that experimental cerebral malaria (ECM) is associated with microvascular plugging (sequestration of pRBCs, leukocytes and platelets), blood brain barrier (BBB) compromise, parenchymal petechial hemorrhages and edema (Medana, Chaudhri et al. 2001; Penet, Viola et al. 2005). Histology is the least expensive morphological technique, which enables examination of large areas of tissue, but all the lesions described above are not specific for malaria.

\subsection{Retinal changes associated with $\mathrm{CM}$}

A postmortem study from Taylor et al (Taylor, Fu et al. 2004) raised an important question of how to accurately diagnose cerebral malaria. They found that one quarter of patients clinically diagnosed as cerebral malaria had an alternative cause of death, with no histopathologic findings typical of cerebral malaria. The retinal and cerebral circulations share a common embryologic origin, therefore changes identified by ophthalmoscopy at the fundus could be very helpful to accurately diagnose cerebral malaria (White, Lewallen et al. 2009; Beare, Lewallen et al. 2011). To this end, a case-control study was conducted during 1996 to 2008 in Malawi to analyze the differences in clinical and/or pathological alterations between children dying from CM and those dying of other deadly infectious diseases (White 2011). This project [supported by the National Institutes of Health (NIH) and named the Blantyre Malaria Project (BMP)] emphasized the application of the fundus as a tool to help diagnosis and prognosis for CM. All of the CM patients were asked to receive a full examination of eyes. At the end of 2008, 90 autopsies were performed among 352 deceased individuals. The patients' eyes were also removed for pathological analysis and clinicopathological correlation. Through this project, a clinicopathologic correlation of retinal hemorrhages with brain bleeding was substantially established, and they established 
the diagnostic criteria for malaria retinopathy based on their findings of retinal hemorrhages as well as three other pathological changes (White 2011), papilledema, an unusual discoloration of the retinal vessels, and a patchy whitening of the retina surrounding the fovea and in the periphery (White 2011). Today, malarial retinopathy is widely accepted as a diagnostic and prognostic factor in human cerebral malaria (White, Lewallen et al. 2009; Combes, El-Assaad et al. 2010). It has been strongly recommended that retina examination become a routine technique to assess a comatose child or adult when CM is a possible diagnosis (Beare, Lewallen et al. 2011). However, a key limitation of the retinal assessment is the subjective nature of ophthalomoscopy and its dependence on the expertise of the examining physician.

\subsection{Magnetic resonance imaging}

The first in vivo magnetic resonance on experimental CM was performed by Penet et al in 2005 (Penet, Viola et al. 2005). Magnetic resonance imaging (MRI) and magnetic resonance spectroscopy (MRS) are noninvasive and quantitative techniques which can identify not only structural but also functional and metabolic changes in experimental CM. They have confirmed characteristics of severe brain edema, parechymal tissue damage, cerebral hemorrhages, BBB disruption (Penet, Viola et al. 2005), and reduced cerebral blood flow in ECM (Penet, Viola et al. 2005). The hemorrhages mostly occurred in the corpus callosum. Crushing of the cerebellum and the pituitary gland, distortion of the brain stem and cerebellum are also frequently observed. These noninvasive and quantitative techniques will be as promising as surrogate tools used to monitor the progression of malaria and the efficacy of anti-malaria treatments (Penet, Viola et al. 2005; Vyas, Gupta et al. 2010; Rasalkar, Paunipagar et al. 2011). The BMP project (see 2.2) is conducting a magnetic resonance imaging scan to assess association between the brains of living individuals and prognosis of CM (White 2011). However, MRI systems are very expensive, emphasize the need to consider strategies that most severe malaria patients who are from underdeveloped African countries could afford.

\section{Functional abnormalities commonly associated with $\mathrm{CM}$}

Cognitive impairment. CM in children is not only related to high mortality but also long-term neurocognitive sequelae (Casals-Pascual, Idro et al. 2008). Children with CM developed new neurological deficits such as gross motor, sensory, and language problems significantly more than corresponding controls (Birbeck, Molyneux et al. 2010). Many children with severe malaria suffer from intracranial hypertension caused by brain endothelial injury, apoptosis, and BBB dysfunction (Idro, Marsh et al. 2010). Intracranial hypertension compromises brain perfusion, nutrient and oxygen delivery leading to global ischemic injury, herniation, brainstem compression, and death (Walker, Salako et al. 1992; Newton, Crawley et al. 1997). Many children with severe malaria are discharged with spastic quadriplegia and severe learning disability (Newton, Crawley et al. 1997). Even if the gross neurological function can be almost completely recovered, hypoxia due to under-perfusion in multiple small areas still leaves many children with cognitive deficiencies (Idro, Marsh et al. 2010). In several retrospective and prospective studies, cognitive dysfunction in children with CM have been found to occur more frequently, and persist far longer than physical and neurologic deficits (Dugbartey, Spellacy et al. 1998; Holding, Stevenson et al. 1999; Carter, 
Mung'ala-Odera et al. 2005; Carter, Lees et al. 2006; Boivin, Bangirana et al. 2007; John, Bangirana et al. 2008). 11.8\% of surviving children had deficits particularly in vocabulary, receptive and expressive speech, word finding and phonology, concomitant with concurrent impairment in nonverbal functioning, memory or attention (Carter, Lees et al. 2006). The duration of seizures and extended comas are related to persistent cognitive deficits (Boivin, Bangirana et al. 2007).

Coma. Marsh et al (Marsh, English et al. 1996; Idro, Marsh et al. 2010) divided CM into four distinct groups based on the severity of neurological dysfunction (Marsh, English et al. 1996; Idro, Marsh et al. 2010). They are summarized as follows: 1) prolonged postictal state, patients in this group usually become conscious within 6 hours with complete neurological recovery. 2) covert status epilepticus, patients in this group are at high risk of aspiration resulting from hypoxic and hypercarbic status caused by hyperventilation. The length of the seizure will determine the patients' neurocognitive outcome. 3) severe metabolic derangement, deaths of patients were reported to be highly related to hypoglycemia and acidosis. 4) primary neurological syndrome, coma which may be caused by intracranial sequestration may persist for one to two days, often accompanied by intracranial hypertension (Marsh, English et al. 1996; Idro, Marsh et al. 2010).

Epilepsy. The incidence of epilepsy occurs in around 10\% of children months to years after exposure to hypoxia (Ngoungou and Preux 2008; Birbeck, Molyneux et al. 2010), and increases with time (Opoka, Bangirana et al. 2009). Epilepsy in malaria is believed to be caused by the focal hypoxic/ischemic neural injury or global ischemic injury (Newton, Peshu et al. 1994; Crawley, Smith et al. 1996; Potchen, Birbeck et al. 2010). The morbidity of epilepsy is positively associated with the timing of exposure to hypoxia (Ngoungou and Preux 2008; Opoka, Bangirana et al. 2009). However, behavior and neuropsychiatric disorders did not differ significantly (Birbeck, Molyneux et al. 2010).

Malaria prophylaxis using sulphadoxine-pyrimethamine combined with amodiaquine was reported to improve cognitive function and school performance in clinical trials when compared to placebo groups (Clarke, Jukes et al. 2008). Similar phenomenon was found in an animal study by Reis et al (Reis, Comim et al. 2010), who support the view that cognitive dysfunction is sustained after rescue treatment in PbA-infected CM-sensitive C57BL/ 6 mice, an animal model for CM. In addition, treatment of CM-sensitive C57BL/6 mice with additive antioxidants such as malondialdehyde, MDA and conjugated dienes along with chloroquine prevented the development of persistent cognitive damage. This indicates that cognition problems may be associated with deleterious reactive oxygen species released during infection.

\section{Effects of cellular and humoral components in $\mathrm{CM}$ pathogenesis}

\subsection{Endothelial cells and parasitized red blood cells}

Endothelial cells. One major feature of $\mathrm{CM}$ is the sequestration of pRBCs in brain microcirculation through adhesion between pRBCs and endothelial cells. The adhesion of falciparum parasitized erythrocytes to the human cerebral microvascular endothelium enables the parasites to avoid splenic clearance (D'Ombrain, Voss et al. 2007) providing the biological basis for the sequestration of $\mathrm{pRBCs}$, and the major feature of $\mathrm{CM}$. The surface receptors on endothelial cells are responsible for adhesion. The major surface receptors on 
endothelial cells are Intercellular Adhesion Molecule 1 (ICAM-1) and CD36 (Collins, Read et al. 1995; Tripathi, Sullivan et al. 2006; Tripathi, Sha et al. 2009). CD36 is an 88-kDa integral protein found on the surface of not only endothelial cells, but adipocytes, platelets, monocytes, and macrophages. ICAM-1 is a $90-115 \mathrm{kDa}$ transmembrane glycoprotein expressed on a variety of cell types including endothelial cells (Ochola, Siddondo et al. 2011). Other endothelial surface antigens include PECAM-1, hyaluronic acid, chondroitin sulfate A (CSA), thrombospondin (TSP), $\operatorname{av\beta 3}$ and E-selectin, P-selectin, vascular cell adhesion molecule-1 (VCAM-1) (Schofield and Hackett 1993; Ho, Hickey et al. 2000; Craig and Scherf 2001; Yipp, Hickey et al. 2007). The sequestration of pRBCs in brain microcirculation in CM is due to the erythrocyte membrane protein 1 (pfEMP-1) expressed on P.falciparum parasitized RBCs adhere to endothelium through the endothelial surface receptors (Kang and McGavern 2010), mainly ICAM-1 and CD36. The interactions between pRBCs (not normal erythrocytes) and vascular endothelium through cellular adhesion molecules induce the deleterious endothelial cell responses (Combes, El-Assaad et al. 2010), including inflammation, endothelial activation, and apoptosis of microvascular endothelial cells resulting in the disruption of the blood-brain barrier (Idro, Marsh et al. 2010) in $P$. falciparum malaria. Apoptosis sequentially occurred in different cells. In murine models, apoptosis occurs in endothelial cells first, and is followed by neuronal and glia cells (Lackner, Burger et al. 2007). P. falciparum-pRBCs increase the expression of ICAM-1 and CD36 (Collins, Read et al. 1995; Tripathi, Sullivan et al. 2006; Tripathi, Sha et al. 2009) which strengthens sequestration, probably through NF-kappa B (Collins, Read et al. 1995; Tripathi, Sullivan et al. 2006; Tripathi, Sha et al. 2009) and MAP Kinase activation (Yipp, Robbins et al. 2003). In addition, pRBC adhesion to endothelium was found to up regulate several TNFsuperfamily genes and apoptosis-related genes such as Bad, Bax, caspase-3, SARP2, DFF45/ICAD, IFN-g receptor2, Bcl-w, Bik, and iNOS (Pino, Vouldoukis et al. 2003). It is worthy to note that direct contact between pRBC and microvascular EC may not be required for triggering apoptosis, because soluble factors released from parasitized erythrocytes have apoptotic effects on HBVEC and neuroglia cells (Wilson, Huang et al. 2008). The heterogeneity of endothelium in various locations of the body, characterized by the difference in expression levels of CD36 or ICAM-1 would probably determine the type and severity of malaria. Most recent results indicated that increased binding to CD36 by parasites is associated with uncomplicated malaria, since little CD36 is expressed on brain microvasculature (Ochola, Siddondo et al. 2011); while binding to ICAM-1 by parasites is increased and is associated with cerebral malaria (Ochola, Siddondo et al. 2011). Chilongola et al argued Ochola's finding, and they suggested that CD36 deficiency may protect against falciparum malarial anemia (Chilongola, Balthazary et al. 2009). Further studies are required to clear out these arguments. Another big change in endothelial cells in CM is the damage of microvasuclar repair which is associated with low levels of circulating endothelial progenitor cells (CD34+/VEGF2+ and CD34+/CD133+) (Gyan, Goka et al. 2009). Together, activation of endothelial cells in brain vascular system by pRBC is one of the key events leading to encephalopathy.

Parasitized red blood cells. pfEMP-1, a variable antigen expressed by P. falciparum (D'Ombrain, Voss et al. 2007), is encoded by the var-gene family of $P$. falciparum (Ikenoue, Kawazu et al. 2002). As we described before, this knob protein plays a significant role in the pathophysiology of CM (Sharma 1997). pfEMP-1protein (Ikenoue, Kawazu et al. 2002) interacts with the endothelial cell through adhesion molecules in a receptor-ligand 
dependent manner (D'Ombrain, Voss et al. 2007). Ultrastructural studies found an attachment between pRBC knobs and endothelial cell microvillus protrusions (Tripathi, Sullivan et al. 2006). pfEMP-1 has been considered a good candidate antigen for vaccination and a molecular therapeutic target to reverse the cytoadherence process (Sharma 1997). In addition, PfEMP-1 suppresses the production of the cytokine interferon-gamma (IFNY) produced by human peripheral blood mononuclear cells ( $\gamma \delta T, N K$, and $\alpha \beta T$ cells), which is a receptor (CD36)- independent (D'Ombrain, Voss et al. 2007). Down-regulation of the proinflammatory IFN- $\gamma$ responses has some beneficial effects for parasite growth. Taken together, changes in RBCs phenotype by falciparum infections trigger activation of cerebral microvascular endothelial cells resulting in falciparum related encephalopathy.

\subsection{Leukocytes}

Monocyte sequestration has recently been acknowledged to play a role in human $\mathrm{CM}$ and murine ECM (Grau, Fajardo et al. 1987; Combes, El-Assaad et al. 2010). Fatal malaria caused by $P$. falciparum is associated with both neutrophil activation and subsequent endothelial damage. For example, apoptosis induced by secretory products of neutrophils plays a key role in endothelial cell damage (Hemmer, Lehr et al. 2005). An antioxidant such as ascorbic acid and a protease inhibitor such as ulinastatin have been used to dramatically decrease falciparum-activated neutrophil-associated endothelial apoptosis (Hemmer, Lehr et al. 2005). The role of CD4+, CD8+, NKT and oy T cells will be described elsewhere (see 4.5 Immunity to malaria).

\subsection{Platelets}

Endothelial cell activation plays an important role in the pathogenesis of cerebral malaria. Rosetting pRBCs bind to the endothelial cells and occlude microvessels in the brain (Cox and McConkey 2010). Therefore, it is not surprising that thrombocytopenia is a common feature in both murine ECM and human CM (Wassmer, Combes et al. 2003; Combes, ElAssaad et al. 2010). Thus, it is essential to understand the association between platelets, pRBCs, leukocytes and endothelial cells in CM. CM is characterized by the accumulation of circulating cells including platelets within brain microvessels (Faille, Combes et al. 2009). Sequestration and accumulation of platelets in various organs, especially in the brain may partly explain the decrease in platelet count in circulation (Wassmer, Combes et al. 2003; Combes, El-Assaad et al. 2010) in malaria disease.

There is increasing evidence that platelets contribute to the pathogenesis of cerebral malaria. Platelets modulate cytoadherence of pRBCs to brain endothelial cells in vitro (Faille, Combes et al. 2009). Animal studies indicate that blocking platelet function in mice is protective against severe malaria (Sun, Chang et al. 2003; van der Heyde, Gramaglia et al. 2005; Wassmer, Combes et al. 2006). Platelets and endothelial cells share common receptors, such as CD36, the complement receptor gC1qR/HABP/p32, and PECAM-1. CD36 and PECAM-1 are receptors for pRBCs (Treutiger, Heddini et al. 1997; Pain, Ferguson et al. 2001; Biswas, Hafiz et al. 2007). Interactions between PfEMP1 on Plasmodium and CD36 on platelets possibly lead to platelet activation. The platelet activation aggregates pRBCs and platelets resulting in occlusion of microcirculation and activation of the endothelial cells (Cox and McConkey 2010). gC1qR/HABP/p32 interacts with both pRBCs and platelets potentiating 
clumping of pRBCs (Biswas, Hafiz et al. 2007). The pathogenic role of platelets can be summarized as follows. First, in vitro cocultures from Wassmer et al (Wassmer, de Souza et al. 2006) showed that platelets or pRBC have a direct cytotoxic effect on TNF- or LT-alphaactivated human brain vascular endothelial cells (HBVEC); second, platelets potentiate the cytotoxicity of pRBC activated HBVEC cells. Both permeability and trans-endothelial electrical resistance (TEER) are strongly affected, and the apoptosis rate of HBVEC cells dramatically increase. Inhibition of platelet adherence to brain microvessels protects against severe P. berghei malaria (Sun, Chang et al. 2003; van der Heyde, Gramaglia et al. 2005); third, studies evaluating interactions of platelet-RBC-endothelium suggest that pathogenic effects of platelets are not caused by adherence to the endothelial cells but result from the regulation of cytokine production (van der Heyde, Gramaglia et al. 2005; Cox and McConkey 2010). It has also been reported that there are more than 300 biologically active proteins in platelet extracts (Coppinger, Cagney et al. 2004), which play a crucial role in activation of endothelial cells (Coppinger, Cagney et al. 2004). As such, platelets can increase leukocyte adhesion to endothelial cells via IL-1, fibrinogen, ICAM-2 and P-secletin (McEver 2001); fourth, micro-particles released from platelets can increase adhesion between endothelium and leukocytes and platelets via ICAM-1 (Barry and FitzGerald 1999; Combes, El-Assaad et al. 2010).

However, effects to target platelets as therapy for cerebral malaria have resulted in controversy. Some studies argue that platelets have a protective role in malaria (Polack, Delolme et al. 1997; Wassmer, Taylor et al. 2008), while others argue the opposite view. Such inconsistencies might be explained by the different roles platelets play. For example, platelet activation will produce thrombocytopenia, which may be an adaptive response to plateletinduced RBC clumping (Wassmer, Taylor et al. 2008).

\subsection{Immunity to malaria}

Immune responses are crucial factors in the pathophysiology of cerebral malaria, both in its initiation and progression. Parasite-triggered immune response and inflammation are considered to be a probable cause of death from CM associated encephalopathy. Innate immunity is generated by neutrophils, NK, NKT, dentritic cell (DCs) and oүT cells; while adaptive immunity is produced by CD4+, CD8+ T cells. B cells and NK cells are not requisite for CM pathology (Yanez, Manning et al. 1996), but NK cells are involved in CXCL10-induced CXCR3+T cells trafficking leading to cerebral diseases and fatalities (Hansen, Bernard et al. 2007). NKT cells are specialized cells coexpressing NK and T cell receptors. They produce high levels of IFN- $\gamma$ and IL-4 after activation, and therefore influence Th1/Th2 immune responses. Thus, the polarization of Th1/Th2 immune responses will determine malarial fatalities (Hansen, Siomos et al. 2003). In a mouse model utilized by Seixas et al, DCs are activated in response to pRBCs internalization, and are important in shaping the adaptive immune response to severe malaria (Seixas, Moura Nunes et al. 2009).

ECM involving P. berghei ANKA is considered a T cell-mediated disease. Both CD4+ and CD8+ T cells are involved in ECM (Belnoue, Potter et al. 2008). Treatment with anti-CD4 or anti-CD8 antibodies protected against ECM (Hermsen, van de Wiel et al. 1997). Studies in malaria patients also indicate higher frequencies of peripheral blood CD4(+) Foxp3(+) CD25(+) regulatory $\mathrm{T}($ Treg) cells which correlate with increased blood parasitemia (Haque, 
Best et al. 2010). In contrast, CD4+ natural regulatory T cells [CD4(+) Foxp3(+) CD25(+), Treg] in animals prevent cerebral malaria via CTLA-4 (but not IL-10) when expanded in vivo. In addition to $\mathrm{CD} 4+\mathrm{T}$ cells, studies from a murine $\mathrm{CM}$ model also confirmed that CXCL10/CXCR3 interactions in the pathogenesis of fatal CM is through the recruitment and activation of pathogenic CD8+ T cells (Belnoue, Potter et al. 2008; Van den Steen, Deroost et al. 2008). The reason why CXCR3-/- mice were resistant to CM is potentially due to a reduction in the number of CD8+ T cells (Miu, Mitchell et al. 2008). Consistent with this, adoptive transfer of CD8+ cells abrogated protection of CM in CXCR3-/- and CXCL10-/mice against $P$. berghei-mediated ECM. CD8+ cytotoxic T cells are involved in the disruption of BBB by perforin-dependent process. Interestingly, only CD8+ cells which were located in microvessels, expressed perforin, induced granule exocytosis and cytolysis (Nitcheu, Bonduelle et al. 2003; Miu, Mitchell et al. 2008), and activated cytotoxicity in a Fas dependent pathway (Nitcheu, Bonduelle et al. 2003; Miu, Mitchell et al. 2008). ECM induction was not only dependent on CD8(+) T cell-derived perforin but also on granzyme B (GzmB) (Haque, Best et al. 2011). CD8+ T cell-mediated CM pathology is characterized as organ-specific; it only occurs in the brain not the liver (Haque, Best et al. 2011). McQuillan et al (McQuillan, Mitchell et al. 2011) indicated that protection against CM was associated with a reduction in the accumulation and activation of CD8+ $\mathrm{T}$ cells in the cerebral microcirculation, along with reduction in malaria parasite burden in the same area (McQuillan, Mitchell et al. 2011). A breakthrough in malaria immunity research is that classical anti-plasmodial drugs act on the immune system in addition to their antiplasmodial activities. Quinine treatment reduced local cytokines and chemokines and coincided with protection against the disease (McQuillan, Mitchell et al. 2011). Artemisinin and its derivatives have been shown to reduce CD4+ and CD8+ $\mathrm{T}$ cell inflammatory responses (Veerasubramanian, Gosi et al. 2006; Wang, Tang et al. 2007; Wang, Qiu et al. 2007; Xu, He et al. 2007). Yanez et al indicated that $\gamma \delta$ T cells, in addition to CD4+ and CD8+ $\mathrm{T}$ cells, have an essential role to play in the pathogenesis of CM (Yanez, Batchelder et al. 1999).

\subsection{Astrocytes, microglia, blood brain barrier}

Studies from a rodent model and human postmortem tissue suggest that the activation of astrocytes and microglial cells occurs during pathogenesis of CM (Medana, Hunt et al. 1997; Medana, Day et al. 2002; Medana and Turner 2006; Szklarczyk, Stins et al. 2007). Accumulation of macrophages and proliferation of microglial cells in the brain play important roles in CM. They increase the adherence of pRBCs to the cerebral microvasculature by secretion of proinflammatory mediators, disruption of BBB, and recruitment of inflammatory cells to the local area, resulting in the brain pathophysiological changes in these patients. An elegant study on the retina by Medana et al (Medana, ChanLing et al. 1996; Medana, Chan-Ling et al. 2000) emphasized the importance of the immune system in the activation of glial cells and consequently in the formation of CM. Because the retina and the brain share similarities in development and function, they used retinal astrocytes and microglial cells to study the function of astrocytes and microglia in the pathogenesis of ECM (Medana, Chan-Ling et al. 1996; Medana, Chan-Ling et al. 2000). Activation of astrocytes and microglia were both observed during fatal murine cerebral malaria using the retinal whole-mount technique (Medana, Chan-Ling et al. 1996; Medana, Chan-Ling et al. 2000). They found that the disruption of blood retinal barrier (BRB)/BBB by 
parasites initiated morphological and distributional changes in astrocytes and microglia. However these mild changes and redistribution were not sufficient for the development of cerebral pathology. The loss of astrocyte ensheathment of vessel segments and the reactive microglia changes resulting in severe cerebral pathology will require immune system activation triggered by the malaria parasites (Medana, Chan-Ling et al. 1996; Medana, ChanLing et al. 2000).

Activated astrocytes and microglial cells are capable of secreting a wide range of cytokines/chemokines, expressing MHC class II and co-stimulatory molecules (Dong and Benveniste 2001; Combes, El-Assaad et al. 2010). Thus they contribute to inflammatory responses within the brain parenchyma in CM (Deininger, Kremsner et al. 2002). Microglia and astrocytes produce TNF-alpha during the course of the disease (Medana, Hunt et al. 1997), which plays a key role in the pathogenesis of fatal CM (Lucas, Lou et al. 1997). Astrocytes express TNF receptor 1 (TNFR1), TNF receptor 2 (TNFR2), IL-1 receptor 1, IFN $\alpha / \beta$ receptor, IFN- $\gamma$ receptor, and macrophage colony-stimulating factor (M-CSF) receptor (Tada, Diserens et al. 1994). TNF-a induces astrocytes to generate and secret colony stimulating factors M-CSF, granulocyte colony-stimulating factor (G-CSF) and granulocyte macrophage colony-stimulating factor (GM-CSF), IL-6 and TNF- $\alpha$ itself (Benveniste 1992). TNF-a and IL-1 induce astrocytes to produce pro-inflammatory cytokines and nitric oxide (Aloisi, Borsellino et al. 1995). Nevertheless, in vivo, astrocytes limit the immune response within the central nervous systems (CNS) and initiate repair processes (Eddleston and Mucke 1993; Mucke and Eddleston 1993). Microglia, when stimulated by LPS and IFN-ץ (Giulian, Baker et al. 1986; Frei, Siepl et al. 1987), produce and release IL-1 (Giulian and Lachman 1985; Giulian, Baker et al. 1986; Giulian, Young et al. 1988), IL-6 and TNF-a (Frei, Malipiero et al. 1989; Medana, Hunt et al. 1997). IL-1 is mitogenic to astroglia (Giulian, Baker et al. 1986). In malaria, any factors (such as CD8+T cells) inducing damage to the microvascular endothelium can result in the leakage of cytokines, malaria antigens and other potentially harmful molecules across the BBB into the brain parenchyma. All of these, in turn, result in the activation of microglia and the activation and apoptosis of astrocytes (Hunt, Golenser et al. 2006) to exacerbate the CM syndrome.

The degree of immune activation and degeneration of glial cells reflect the extent of neurological complications in murine ECM (Medana, Chaudhri et al. 2001). Astrocyte disruption will cause acute or chronic damage to brain function. Damage to astrocytes, a major source of kynurenic acid may result in reduced production of the neuroprotectant molecule kynurenic acid (Medana, Hien et al. 2002; Medana, Day et al. 2003; Hunt, Golenser et al. 2006), causing a decrease in its ratio relative to the neuroexcitotoxic molecule quinolinic acid, which might contribute to some of the neurological symptoms of ECM and CM (Medana, Hien et al. 2002; Medana, Day et al. 2003; Hunt, Golenser et al. 2006). Redistribution, changes in gene expression, and the death of astrocytes have all been reported in human CM and ECM (Medana, Idro et al. 2007). Astrocyte ensheathment of vessels was associated with a big increase in BBB permeability that occurs at the time of neurological complications in the murine models of malaria. The loss of astrocyte processes was associated with the adherence of monocytes to the vascular endothelium, suggesting that toxic products produced by monocytes might play a role in astrocyte degeneration (Medana, Chaudhri et al. 2001). Microglia were found to be concentrated around capillaries in the grey matter. However microglia containing neutral lipid and iron pigment were 
found in large perivascular lesions in the white matter. In addition, microglia were associated with perivenular haemorrhages (Medana, Chaudhri et al. 2001). Activation of microglia might damage astrocytes via Fas/FasL interactions (Potter, Chan-Ling et al. 2006). These findings underline the important contribution within the CNS of glia and their secreted products, such as cytokines, in the development of human CM.

\subsection{Microparticles (MP) and CM}

Eukaryotic cells, after activation by a variety of stimuli, shed components of their plasma membranes into circulation. Such submicron particles may include cytoplasmic and nuclear (Roos, Gennero et al. 2010) elements and are known colloquially as microparticles (MPs) (Barry and FitzGerald 1999; Doeuvre, Plawinski et al. 2009). Monocytes, lymphocytes, endothelial cells, erythrocytes, granulocytes and platelets have been shown to vesiculate either in vitro or in vivo (Barry and FitzGerald 1999). MPs, exposing the phospholipid phosphatidyl serine (PS) on the external surface of the cell membrane (Schroit, Madsen et al. 1985), have been identified increasingly in a broad range of diseases (Roos, Gennero et al. 2010) where vascular dysfunction and inflammation are important pathophysiological mechanisms (Lynch and Ludlam 2007).

Human studies (Combes, Taylor et al. 2004) on MPs in CM were first conducted in Malawian patients demonstrated that increased release of circulating endothelial cellderived MP- (EMPs) correlate with malaria severity. EMPs are increased in patients with severe CM complicated with coma (Barry and FitzGerald 1999; Doeuvre, Plawinski et al. 2009), but not with those with malaria complicated by anemia. The high concentrations of plasma TNF in patients with CM may enhance endothelial vesiculation both in vivo and in vitro (Combes, Simon et al. 1999). In a P. berghei (PbA) infected ECM mouse model, ABCA1, a gene determining the lipid transbilayer remodeling was found to be responsible for external exposure of PS to generate EMPs in malaria (Combes, Coltel et al. 2005).

Apart from endothelium, other cell types including erythrocytes, platelets and monocytes also release microparticles and contribute to the pathogenesis in patients with malaria. Red blood cell-derived microparticles (RMPs) were increased in patients with $P$. falciparum, $P$. vivax, and P. malariae compared with healthy controls (Nantakomol, Dondorp et al. 2011). RMPs were highest in severe falciparum malaria patients. RMPs released from either parasitized erythrocytes or uninfected red blood cells (URBCs) are pathogenic. pRBCs released 10 times more RMPs than did URBCs. Overall, the majority of RMPs were derived from URBCs (Nantakomol, Dondorp et al. 2011). In vitro, RMPs production increased as the parasites matured. Some biological molecules can trigger RMPs release. For example, hemin-mediated oxidative stress was associated with the production of RMPs (Nantakomol, Dondorp et al. 2011). Hemin induced RMP formation in URBCs was inhibited by Nacetylcysteine. In PbA infected C57 BL/ 6 mice (Couper, Barnes et al. 2010), malaria parasitederived plasma MPs which are derived primarily from $\mathrm{pRBCs}$, induced severe inflammation through potent macrophage activation as indicated by CD40 up-regulation and TNF production. Consistent with this, in vitro experiments confirmed that these MPs produced higher levels of macrophage activation than intact infected red blood cells. MPs driven macrophage activation was dependent on MyD88 and TLR-4 signaling (Couper, Barnes et al. 2010). 
Platelets vesiculate particles following activation by complement proteins C5b-9 (Sims, Faioni et al. 1988). It was demonstrated that platelet-derived MPs (PMPs) may modulate adhesive interactions between endothelial cells and monocytes resulting in human atherosclerosis and inflammation (Sims, Faioni et al. 1988). In 2009, Grau's group (Faille, Combes et al. 2009) showed that PMPs derived from activated platelets are able to bind to falciparum-infected RBCs (pRBCs), thereby transferring platelet antigens to the PRBCs surface. PMPs uptake by HBVECs induce changes in the endothelial phenotype, dramatically increasing pRBCs cytoadherence to HBVECs and playing a role in the pathogenesis of P.falciparum (Faille, Combes et al. 2009). PMPs adherence is specific to pRBCs, and require the expression of the pfEMP variant on pRBCs. Not surprisingly, this binding to $\mathrm{pRBCs}$ decreases either after digestion of $\mathrm{pRBCs}$ surface proteins by trypsin or neutralization of PMPs with a mAb to platelet-endothelial cell adhesion molecule-1 (CD31) and glycoprotein IV (CD36) (Faille, Combes et al. 2009).

In a recent human study conducted in Douala, Cameroon (Pankoui Mfonkeu, Gouado et al. 2010) indicated that not only plateletic, erythrocytic and endothelial but also leukocytic MPs levels were elevated in CM patients with neurological dysfunctions but return to normal levels after recovery of patients. This vesiculation in the vascular compartment is a characteristic of CM but not of SMA. Platelet MPs were the most abundant and their levels significantly correlated with the depth of unconsiousness and thrombocytopenia. Their findings raise the importance of $\mathrm{MP}$ as a biomarker of cerebral involvement and the importance of the intervention to block MPs production as a new therapeutic strategy in CM (Pankoui Mfonkeu, Gouado et al. 2010). Whether MPs can be detected and identified in CSF or other body compartments (saliva) as a predictor of cerebral tissue damage is unclear.

Various techniques including flow cytometry (FC), enzyme-linked immunosorbent assay (ELISA), and functional assays have been used to detect circulating MPs (Azevedo, Pedro et al. 2007; Lynch and Ludlam 2007). 1) FC is the most common method to quantify MPs. The advantages of FC are simplicity and the wealth of data generated from study samples. However, the small size of MPs and the lack of uniformity in methodology complicate measurement of outcomes. As MPs contain surface and cytoplasmic contents of the parent cells (particles which reflect their cell of origin and its state of activation) and contain phosphatidylserine, antibodies against specific cell surface markers and annexin V can be used for detection. FC can be used to quantify and identify MPs of different cellular origin (Doeuvre, Plawinski et al. 2009; Campos, Franklin et al. 2010; Roos, Gennero et al. 2010). 2) Since FC is too expensive and not feasible in most clinical centers, an ELISA for PMPs has recently been developed as a viable alternative for the clinical measurement of PMPs levels (Shirafuji, Hamaguchi et al. 2008; Nomura, Shouzu et al. 2009). ELISA can be performed after freezing the sample, allowing samples to be batched for assays, and thus reducing expenses. The PMPs ELISA kit used two monoclonal antibodies against glycoprotein CD42b and CD42a (Shirafuji, Hamaguchi et al. 2008; Nomura, Shouzu et al. 2009). One unit/milliliter of PMPs was defined as 24,000 platelets/ml of solubilized platelets in this ELISA system.

Recently, new methods have been introduced to assay for MPs. SYTO 13 is a more sensitive quantitative assay for MPs (Ullal, Pisetsky et al. 2010). The emergence of SYTO13 dyes for detection of MPs is attributed to limitation of FC with either light scatter or surface marker staining due to the small size of MPs $(0.05$ to $1.5 \mu \mathrm{m})$. The SYTO 13 assay is based on the principle that MPs contain DNA and RNA, thus allowing SYTO13 to bind both DNA and 
RNA within particles. STYO 13 enhanced the ability of the detection for particles 1.5-2.9 times more than did light scatter in FC (Ullal, Pisetsky et al. 2010). Circulating nucleic acids (CNAs) have been increasingly recognized as powerful diagnostic and prognostic tools for various inflammatory diseases (Ullal, Pisetsky et al. 2010). For example, CNAs level as measured by amplification of the human telomerase reverse transcriptase (hTERT) gene, or the dsDNA quantification were significantly increased in plasma from $P$. vivax patients compared with healthy controls (Ullal, Pisetsky et al. 2010). No such report is available for malaria encephalopathy.

\section{Molecular pathogenesis of $\mathrm{CM}$}

\subsection{Crosstalk and signaling pathways in $\mathrm{CM}$}

\subsubsection{Cytokines and chemokines}

Cytokines and chemokines exert both protective and harmful effects during CM pathogenesis. Antigen-like components released from malaria induce both pro and antiinflammatory cytokines and chemokines. The balance between these biological mediators is crucial for parasite control and for the contribution to the pathogenesis of severe malaria and CM encephalopathy (Idro, Marsh et al. 2010).

\subsubsection{Th1 and Th2 cytokines}

The harmful, dysregulated immune response resulting in CM or ECM is mainly due to the imbalance between Th1 and Th2 types with overproduction of some cytokines, such as IFNY combined with underproduction of others such as IL-10.

Th1 cytokines include IFN- $\gamma$ and lymphotoxin (TNF-beta). CD4+ Th cells are subdivided into two different types, known as type 1 Th (Th1) and type 2 Th (Th2). Th1 cells produce cytokines, such as IL-2, IFN- $\gamma$ (at a later stage also by CD8+ cytotoxic T cells), tumor necrosis factor (TNF-alpha) and TNF-beta, which cause the activation of macrophages and the process of opsonization and cytotoxicity (Romagnani 1997). In contrast, Th2 cells are considered to play a regulatory and protective role, since cytokines produced by these cells [e.g., IL-10, transforming growth factor- $\beta$ (TGF- $\beta$ ), IL-4 and IL-13] inhibit the production of Th1 cytokines and activation of macrophages (Romagnani 1997; Hunt and Grau 2003). A recent study in Ghanaian and Indian patients demonstrated an association between fatal $\mathrm{CM}$ and increased serum and cerebrospinal fluid (CSF) levels of proinflammatory and proapoptotic factors including CXCL10, IL-1ra, sTNFR1, sTNFR2, sFas and decreased serum and CSF levels of neuroprotective angiogenic growth factors (PDGFb) (Armah, Wilson et al. 2007). In children with CM, cytokine TNF-a level in CSF is associated with subsequent neurological and cognitive morbidity (John, Panoskaltsis-Mortari et al. 2008).

Th2 cytokines include IL-4, IL-10 and TGF-beta. IL-10 not only plays an important role in cerebral malaria pathogenesis (Yanez, Manning et al. 1996; John, Panoskaltsis-Mortari et al. 2008), but also is associated with asymptomatic malaria in pregnant women (Wilson, Bythwood et al. 2010). TGF $\beta$ isoforms were shown to accumulate in the brain of CM patients. Members of the TGF $\beta$ cytokine family have been associated with the control of malaria infection and parasite growth (Omer and Riley 1998; Hunt and Grau 2003; Chaiyaroj, Rutta et al. 2004); TGF $\beta 1$ levels were significantly reduced in peripheral plasma of children with CM (Omer and Riley 1998; Hunt and Grau 2003; Chaiyaroj, Rutta et al. 
2004). However, a mechanism for CM was found through TGF $\beta 1$ released from activated platelets, by which TGF $\beta 1$ induces TNF-mediated apoptosis in human brain endothelium (Wassmer, de Souza et al. 2006).

Other host serological factors contain CXCL10, interleukine (IL-1), IL-6, IL-8, MCP-1, RANTES. In 2003, CXCL10 was first reported to be a host-protective factor in ECM (Hunt and Grau 2003). CXCL10 expression was expressed early in either cerebral malariasusceptible or -resistant strains of mice to P. berghei ANKA infection (Chen and Sendo 2001; Hanum, Hayano et al. 2003). More recently, a pioneering study conducted both in India and Ghana, identified CXCL10 as a serum and CSF biomarker associated with increased risk of fatal P. falciparum-mediated CM in humans (Armah, Wilson et al. 2007; Jain, Armah et al. 2008; Wilson, Huang et al. 2008). Subsequently, studies from a murine CM model also confirmed the importance of CXCL10/CXCR3 interactions in the pathogenesis of fatal CM through the recruitment and activation of pathogenic CD8+ T cells (Belnoue, Potter et al. 2008; Van den Steen, Deroost et al. 2008). CXCL10-/- and CXCR3-/- mice are partially resistant to $P$. berghei-mediated CM. Furthermore, the study also revealed that CXCR3-/mice were resistant to $\mathrm{CM}$ as a result of a reduction in the number of CD8+ T cells (Miu, Mitchell et al. 2008). Adoptive transfer of CD8+ cells abrogated protection of CM in CXCR3/- mice while CXCL10-/- mice were partially resistant to P. berghei-mediated CM. A proposed cellular pathways of CXCL10-mediated severe malaria is presented in Figure 1 [(Adapted with permission from Cytokine and Growth Review (Liu, Guo et al. 2011) ]. Endothelial cells, astrocytes and microglia are a prominent source of CXCL10 and CXCL9. 1) Through T cells sequestration (Belnoue, Kayibanda et al. 2002; Nitcheu, Bonduelle et al. 2003; Campanella, Tager et al. 2008; Miu, Mitchell et al. 2008). CXCL10 could attract activated $\mathrm{T}$ cells and mediate Th1-type response, characterized by the sequestration of monocytes and T cells (mainly CD8+) in cerebral microvessels. Granule exocytosis and Fas/Fas ligand activation pathways are two distinct mechanisms involved in the death of brain endothelial cells by CD8+ lymphocytes. 2) Through NK cell sequestration (Hansen, Siomos et al. 2003; Hansen, Bernard et al. 2007), NK cells mediate direct cytotoxic activity or reconstitution capacity of T cells to migrate in response to CXCL10 to the CNS. 3) Through up-regulation of ICAM-1 on brain microvascular endothelial cells (Bauer, Van Der Heyde et al. 2002). LTa and IFN-ץ are required for PbA-induced endothelial ICAM-1 up-regulation and $\mathrm{PbA}$-induced increased cytoadherence of sequestered of pRBC to the endothelium of cerebral vessels. This results in hypoxia, hemorrhage and pathology, and represents another potential mechanism of CM pathogenesis.

CXCL10 is elevated in association with chills, rigors, anemia (Jain, Singh et al. 2009) and prechloroquine/primaquine chemotherapy and disappears after chemotherapy against malaria. Interestingly, HIV infection increases susceptibility to malaria when CXCL10 levels are elevated (Chaisavaneeyakorn, Moore et al. 2002) while filariasis produces resistance to malaria by down-regulating CXCL10 (Metenou, Dembele et al. 2009). Recent studies suggest that altered levels of CXCL4 and CXCL10 play a prominent role in the pathogenesis of fatal $\mathrm{CM}$ and may be used as functional or surrogate biomarkers for predicting CM severity (Wilson, Jain et al. 2011). This remarkable link between increased CXCL10 and the severity of parasitic diseases suggest further studies needed to be conducted on the mechanisms involved. (Campanella, Tager et al. 2008). Our recent in vitro cell culture studies (Liu \& Stiles, manuscript in review) revealed that Heme regulates CXCL10 at the transcriptional level [See 5.1.3.1 Heme/ Heme oxygenase-1 (HO-1)]. 


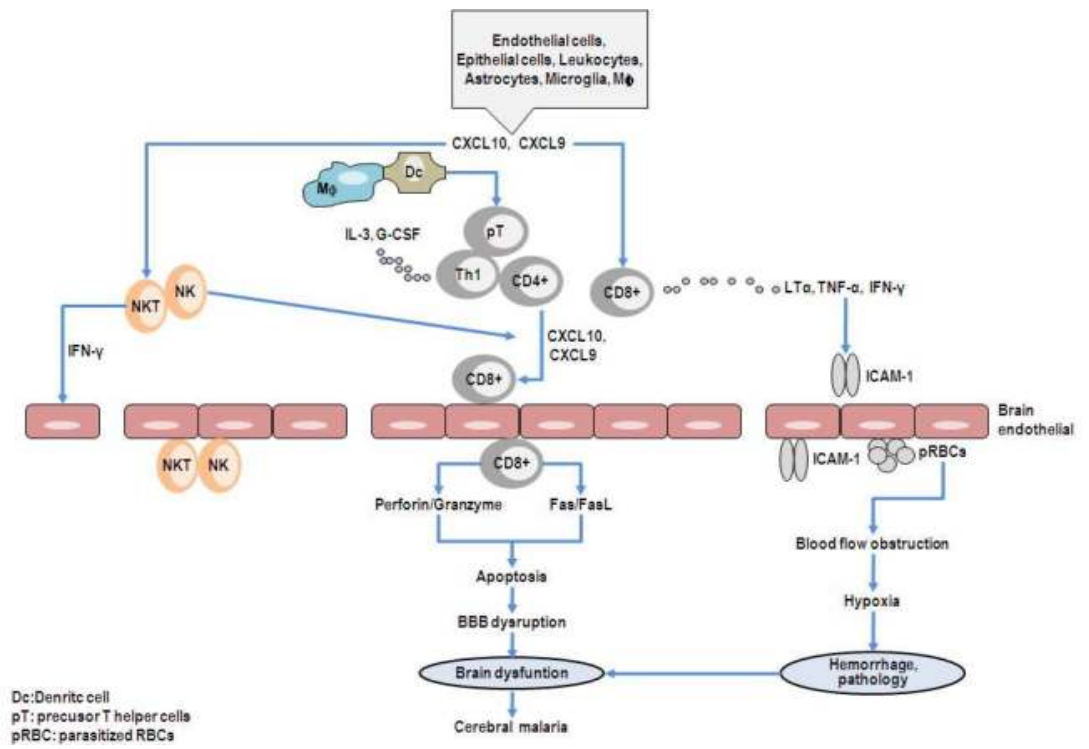

Fig. 1. Proposed cellular pathways in CXCL10-mediated severe malaria.

IL-1 and IL-6 are key pathogenic factors in malaria (John, Panoskaltsis-Mortari et al. 2008). Significantly elevated levels of IL-1, G-CSF and monocyte chemoattractant protein-1 (MCP1) but not IL-8 have been reported in children who died of CM than children without the disease (UM) (John, Park et al. 2008). However, a study on the global transcriptome of HBVEC after exposure to P.falciparum-infected RBCs showed that proinflammatory molecule IL-8 together with CCL20, CXCL11, CXCL2 and IL-6 were increased more than 100 -fold consistent with the critical role of the endothelium in promoting leukocyte infiltration (Tripathi, Sha et al. 2009). Low levels of the chemokine RANTES are independently associated with mortality (John, Opika-Opoka et al. 2006). In summary, the role of cytokines/chemokines and corresponding receptor interactions appear to be highly associated with severity of CM encephalopathy.

\subsubsection{Angiopoiesis and CM (angiogenic/angiostatic factors)}

Vascular endothelial growth factor (VEGF) and Angiopoietin-1 (Ang-1)/ Ang-2. Severe and cerebral malaria are associated with endothelial activation (Conroy, Lafferty et al. 2009). The role of VEGF in CM encephalopathy remains to be clarified. Increased production of VEGF is able to trigger vascular leakage in the circulation of mice, and promote injury in ECM (Epiphanio, Campos et al.) although it can induce antiapoptotic proteins like Bcl2 in endothelial cells (Ferrara 2004). In our study performed in Indian angiogenic and antiapoptotic factors, VEGF was found to be negatively correlated with mortality associated with CM (Jain, Armah et al. 2008), and to be protective against fatal CM (Jain, Armah et al. 2008). ANG-1 and ANG-2 are major regulators of endothelial activation and integrity (Conroy, Lafferty et al. 2009). CM patients have significantly lower ANG-1 levels, significantly higher ANG-2 levels and ANG-2/ANG-1 ratio than non-malaria or malaria patients without cerebral involvement (Conroy, Lafferty et al. 2009). ANG-2 has dual 
functions depending on the activity of endogenous VEGF-A. Lobov et al (Lobov, Brooks et al. 2002) stated that VEGF acts through the conversion of ANG-2 stimulation from anti- to pro-angiogenic to regulate vascularity (Lobov, Brooks et al. 2002). ANG-2 in vivo increases capillary diameter, remodels the basal lamina, promotes proliferation and migration of endothelial cells, and stimulates sprouting of blood vessels when VEGF-A is activated; whereas, ANG-2 promotes endothelial apoptosis and vessel regression if the VEGF activity is inhibited. Plasma levels of ANG-1 and -2 predict cerebral malaria outcome in Central India (Jain, Lucchi et al, 2011). Malar J. 2011 Dec 23;10(1):383.

\subsubsection{Erythropoietin and CM}

Erythropoietin (Epo) regulates the production of new erythrocytes in blood trough binding to its receptor (EpoR) which is expressed on the cell surface of bone marrow erythroid precursors (Casals-Pascual, Idro et al. 2009). During this process, tissue hypoxia activates Epo gene expression (Casals-Pascual, Idro et al. 2009). Epo has recently been recognized as a tissue-protective cytokine (Brines, Grasso et al. 2004). The tissue-protective effects of Epo are mediated by EpoR located on neurons, astrocytes, microglia and endothelial cells (Masuda, Nagao et al. 1993; Masuda, Okano et al. 1994; Bernaudin, Nedelec et al. 2002; Sargin, ElKordi et al. 2011). In other words, the non-hematopoietic function of Epo occurs in organs outside the bone marrow such as brain, retina, spinal cord, peripheral nerves, heart, kidney, and skin (Ghezzi and Brines 2004; Maiese, Li et al. 2005; Arcasoy 2008; Casals-Pascual, Idro et al. 2009). In this case, hypoxia does not have a key role in the regulation of EpoR, whereby Epo, pro-inlammatory cytokines IL-1 and TNF regulate EpoR (Nagai, Nakagawa et al. 2001; Brines and Cerami 2005; Siren, Fasshauer et al. 2009). The distinct functions of Epo are thought to be mediated via different receptors (Brines, Patel et al. 2008; Casals-Pascual, Idro et al. 2009). EpoR homodimers induce the haematopoietic response, whereas tissueprotective actions are induced by a heterocomplex composed of the Epo receptor and other cytokine receptors such as CD131, the beta-common receptor (mediating signals from GMCSF, IL-3 and IL-5) (Brines, Patel et al. 2008). The pleiotropic action of Epo through the heterodimeric EpoR causes anti-apoptotic, anti-inflammatory, anti-angiogenic and antioxidatory effects in a variety of neuropathological disorders (Brines, Grasso et al. 2004; Hasselblatt, Ehrenreich et al. 2006), which might be potentially beneficial in CM. In the $P$. berghei-infected mouse model, Epo activated neural stem cells (NSC) and caused proliferation of NSC and neuronal precursor cells in sub ventricular zone (Core, Hempel et al. 2011). Emerging evidence has shown beneficial effects of recombinant human erythropoietin (rHuEpo) in both experimental and human CM (Casals-Pascual, Idro et al. 2008; Casals-Pascual, Idro et al. 2009; Mishra and Wiese 2009). Experimental CM studies have shown that Epo increases survival, shortens coma recovery times (Bienvenu, Ferrandiz et al. 2008) and decreases the inflammatory response and neuronal apoptosis in the brain (Kaiser, Texier et al. 2006; Wiese, Hempel et al. 2008). Human studies in African children with CM have indicated that Epo prevents brain damage (Casals-Pascual, Idro et al. 2009) and protects against neurological sequelae (Casals-Pascual, Idro et al. 2008). Although a safety profile for short-term (7 days) administration of erythropoietin at high does $(1,500 \mathrm{U} / \mathrm{kg} /$ day during 3 days) combined to quinine have recently been assessed in Mali (Picot, Bienvenu et al. 2009), a multicenter study using Epo as an adjunctive therapy to improve survival during CM is necessary. In summary, the interactions between Epo and EpoR in organs outside bone marrow appear to contribute to the protection against fatal CM pathogenesis although the mechanism is not completely understood. 


\subsubsection{Signaling pathways in $\mathrm{CM}$ encephalopathy}

Cytoadherence between pRBC and endothelial cells is increased by up regulation of endothelial molecules such as ICAM-1, CD36 (Combes, El-Assaad et al.) in severe malaria. The proinflammaotry NF-kappaB pathway (Tripathi, Sha et al. 2009; Labbe, Miu et al. 2010), Src family kinase (Yipp, Robbins et al. 2003; Gillrie, Krishnegowda et al. 2007) and Rho kinase (Taoufiq, Gay et al. 2008) play certain roles in modulating the host response to $P$. falciparum, especially in the interaction between sequestered $\mathrm{pRBC}$ and specific endothelium [Fig. 2, Adapted with permission from Cytokine and Growth Review (Liu, Guo et al. 2011)]. A better understanding of host-parasite interactions will facilitate the development of novel strategies for interventions.

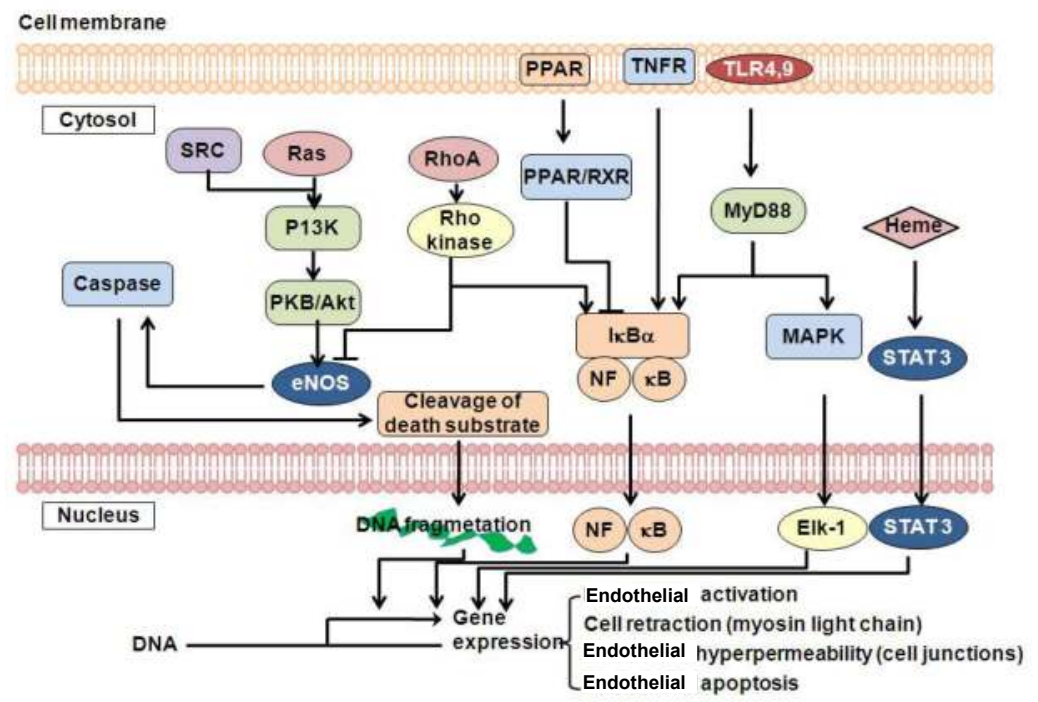

Fig. 2. Kinases and transcription factors in cerebral malaria.

\subsubsection{Rho kinase signaling pathway}

Some endothelial cell surface receptors have an intracellular domain coupled to G-protein and Rho signaling (Taoufiq, Gay et al. 2008). GDP/GTP exchanges and the activation of RhoA activate its downstream molecule Rho kinase. Activated Rho A/Rho kinase pathway leads to endothelial dysfunction by increasing cell retraction (through phosphorylation of myosin light chain) and endothelial hyperpermeability (through tight junction). Rho kinase also downregulates PI3K/Akt/eNOS cell growth pathway (Taoufiq, Gay et al. 2008). Rho kinase inhibitor (HA-1077), a drug already in clinical use, was reported to decrease both NFkappaB activation and endothelial apoptosis (Taoufiq, Gay et al. 2008; Zang-Edou, Bisvigou et al. 2010), increase survival, and delay or prevent development of cerebral malaria (Waknine-Grinberg, McQuillan et al. 2010).

\subsubsection{NF-kB signaling pathway}

pRBCs exposure induced nuclear translocation of NF-kB in HBVEC, which is related to ICAM1 expression. In this way, pRBCs may increase their sequestration, thereby exacerbating $\mathrm{CM}$ (Tripathi, Sullivan et al. 2006). A global gene profile study on HBVECs after interaction with 
pRBCs emphasized that the proinflammatory NF-KB pathway was central to the regulation of the P.falciparum-modulated endothelium transcriptorme (Tripathi, Sha et al. 2009).

\subsubsection{Toll-like receptor (TLR) signaling pathway}

MyD88 is a necessary adaptor molecule for intracellular signaling induced by most TLRs (Coban, Ishii et al. 2007). TLR4, TLR9 and MyD88 were described to play a role in proinflammatory responses to malaria infection following interaction of DC with the malaria parasite (Seixas, Moura Nunes et al. 2009). Both TLR4 and TLR9 besides MyD88 are required for complete DC activation, and consequently up regulation of co-stimulatory molecules, NF-kB nuclear tanslocation and production of cytokines (Seixas, Moura Nunes et al. 2009). Among the MyD88-dependent CM-related innate immunity signaling, TLR2 or TLR9 increases susceptibility to CM-related mortality, suggesting that these two TLRs play a critical role in the pathogenesis, and not in protective immunity (Coban, Ishii et al. 2007). TLR2 stimulation with $P$. falciparum glycosylphosphatidylinositol (PfGPI) increases pRBCs uptake and clearance by macrophage as another example of the role of innate immunity responses to malaria (Erdman, Cosio et al. 2009).

\subsubsection{Peroxisome proliferator activating receptor (PPAR)/PKC signaling pathway}

PPAR-retinoid $X$ receptor (PPARY/RXR) activated phagocytosis of $p R B C s$ and decreased malaria-induced TNF- $\alpha$ secretion by monocytes/macrophages (Serghides and Kain 2001). PPAR has been reported to inhibit the induction of inflammatory genes via PPARYdependent mechanisms, an effect mediated, at least partially, by inhibition of transcription factors NF-kB (Straus, Pascual et al. 2000). PfGPI from P. falciparum has also been shown to be a potent inducer of inducible NO synthase system through the activation of NF-kB (Schofield, Novakovic et al. 1996).

\subsubsection{Signal transducer and activator of transcription (STAT3) signaling pathway}

STAT3 is a signaling cascade activated by pro-inflammatory stimuli and cellular stresses. This protein located in the cytoplasm is in its inactive form and is activated via phosphorylation (pSTAT3) by the Janus tyrosine kinases (JAKs). The active form of STAT3 quickly translocates to the nucleus. pSTAT3 is a potent negative modulator of the Th1mediated inflammatory response, and also an activator of a variety of genes which are important for immune modulation (Yu and Jove 2004; El Kasmi, Holst et al. 2006). Chen's group has reported that lethal Plasmodium yoelii (P.yoelii) induced activation of STAT3 in the early phase of infection. The dominant pSTAT3 response may dampen the development of protective immunity, resulting in high parasitemia and death (Shi, Qin et al. 2008). Our data (Liu \& Stiles, manuscript in review) showed that STAT3 is activated by $\mathrm{PbA}$ infection in vivo and Heme in vitro, while HO-1 regulates STAT3 signaling.

\subsubsection{TNF/TNFR (LTa $\beta / L T \beta R)$ signaling pathway}

$\mathrm{TNF}$, the most extensively investigated cytokine in CM, up regulates ICAM-1 expression on the cerebral vascular endothelial cells and enhances the cytoadhesion of pRBCs (Idro, Marsh et al. 2010). Local synthesis is enhanced close to the sequestration sites. TNF has dual functions in malaria: it may be cytoprotective in the early phase, but its sustained high levels leads to complications (Hunt and Grau 2003; Idro, Marsh et al. 2010). Signaling through TNF receptors activate the classic NF- $\mathrm{KB} /$ RelA pathway resulting in the expression of a large number of genes involved in inflammatory responses, cell adhesion or cell growth (Togbe, 
de Sousa et al. 2008). Unfortunately, neither pentoxifylline, which reduces macrophage TNF synthesis, nor anti-TNF monoclonal antibody increased the survival of patients (Looareesuwan, Wilairatana et al. 1998; Wenisch, Looareesuwan et al. 1998; Idro, Marsh et al. 2010) although the coma period was shortened (Di Perri, Di Perri et al. 1995) or the levels of TNF/TNFR and IL-6 were decreased (Looareesuwan, Wilairatana et al. 1998; Wenisch, Looareesuwan et al. 1998).

\subsubsection{MAP kinase/ Src family kinase pathway}

MAPKs and downstream activation of the ERK and p38 pathways (not shown in Fig.2 for clarity) triggered by PfGPIs regulate TNF- $\alpha$ and IL-12 production, two of the major inflammatory cytokines produced by macrophages stimulated with PfGPIs (Zhu, Wu et al. 2009). Src-family kinase signaling was found to modulate the adhesion of $P$. falciparum on human microvasculature (Yipp, Robbins et al. 2003; Gillrie, Krishnegowda et al. 2007). A novel mechanism for the regulation of pRBCs adhesion on human microvascular endothelial cells is through CD36, Src-family kinase, and ectoalkaline phosphatase (Yipp, Robbins et al. 2003).

\subsubsection{Apoptosis-related genes}

See 4.1 Endothelial progenitor cells and endothelial cell markers

\subsubsection{Other signaling pathways}

\subsubsection{Heme/Heme oxygenase-1 (HO-1)}

Recently, it has been shown that increased levels of free Heme produced during malaria infection induces inflammation that damages host vascular endothelium, which contributes to cerebral pathogenesis and acute lung injury (ALI) which are major features of fatal malaria (Epiphanio, Campos et al. ; Hunt and Stocker 2007; Pamplona, Ferreira et al. 2007; Pamplona, Hanscheid et al. 2009). Heme oxygenase (HO) is the rate-limiting step enzyme in the degradation of Heme groups to biliverdin, carbon monoxide (CO), and iron. HO-1 is also known as a heat shock protein 32 (hsp32), which is an integral membrane protein of the smooth endoplasmic reticulum (Lin, Weis et al. 2007), and is the only inducible isoform of HO. The up regulation of HO-1 provides protection against cellular stress including oxidative stress, heavy metal toxicity, UV radiation, and inflammation, thus preventing deleterious effects of Heme and mediating anti-inflammatory and antiapototic functions (Geuken, Buis et al. 2005; Datta, Banerjee et al. 2010). HO-1 may facilitate the repair of injured tissues through inhibition of infiltrating inflammatory cells (Datta, Dormond et al. 2007). Moreover, HO-1 that is induced by reactive oxygen species and nitric oxide (NO) has recently been shown to be involved in the regulation of angiogenesis (Pae, Oh et al. 2005; Bussolati and Mason 2006).

The expression of HO-1 occurs at low levels in most tissues under physiological conditions (Ehrich and Eke 2007). HO-1 can localize to distinct subcellular compartments. Inducible HO activity appeared in the plasma membrane, cytosol, mitochondria (Ryter and Choi 2009), isolated caveolae and the nucleus (Kim, Wang et al. 2004) in cell culture models. Early studies indicate that HO-1 in the mitochondria and caveolae performs important biological and physiological functions (Ryter and Choi 2009), although the function of HO-1 in caveolae and the nucleus is not completely understood. The nuclear form of HO-1 serves potentially as a transcriptional regulator (Ryter and Choi 2009). Upon different stimuli of hypoxia, hemin or 
Heme-hemopexin, HO-1 translocates to the nucleus. Nuclear translocation compromises HO activity, but nuclear localization of HO-1 protein functions to up regulate genes that promote cytoprotection against oxidative stress (Lin, Weis et al. 2007).

Heme/HO-1 interactions have moved to center stage in CM research since 2007. At the time, Mota's group reported that HO-1 and carbon monoxide (CO) suppressed the pathogenesis of ECM (Pamplona, Ferreira et al. 2007). HO-1 was then found to be capable of inhibiting vascular occlusion in transgenic sickle mice (another hemolytic disease) (Belcher, Mahaseth et al. 2006; Belcher, Vineyard et al. 2010). From these studies it seems that the ability of individuals to respond strongly in response to an increase in HO-1 may be a crucial endogenous protective factor. However, some studies refute the findings that HO- 1 protects the development of ECM (Takeda, Kikuchi et al. 2005). Their data suggests that the frequency of short (GT)n alleles (<28 repeats), which may lead to high levels of HO-1, is markedly higher in CM patients (Takeda, Kikuchi et al. 2005). Moreover, liver stages of malaria infection was remarkably reduced in Hmox1-/- mice (Pamplona, Ferreira et al. 2007). These findings suggest that the regulated expression of HO-1 is quite complex in different tissues at different stages of the Plasmodium life cycle. Therefore further experimental and epidemiological studies are necessary to unveil the role of Heme/HO-1 in the severity of malaria. Our study (Liu \& Stiles, manuscript in review) demonstrated that (1) infection of C57 BL/6 mice with $\mathrm{PbA}$ resulted in significant tissue damage. (2) Heme/HO-1 and CXCL10/CXCR3 are involved in the pathogenesis of severe malaria, such that the level of free Heme is linked to PbA infection in mice. (3) Expression of HO-1 in tissues may be protective against $\mathrm{PbA}$ induced Heme-associated damage. (4) High levels of CXCL10 are associated with ECM onset in PbA infected mice. (5) Heme up regulates HO-1 and CXCL10 production in vitro, and regulates CXCL10 at the transcriptional level in vitro. (6) HO-1 transcription was positively regulated by CXCL10. Overall, our results demonstrate that Heme and CXCL10 molecules as well as related signaling pathways play a very important role in inflammation and organ damage in malaria and CM encephalopathy.

\subsubsection{Arginine/Nitric oxide signaling pathway}

The role of Nitric oxide (NO) in malaria pathogenesis has been inconsistent. The relationship between $\mathrm{NO}$ activity and inducible $\mathrm{NO}$ synthase and pathogenesis is controversial (Anstey, Weinberg et al. 1996; Cramer, Nussler et al. 2005). NO exerts effects in host defense, neurotransmission, and vascular maintenance. NO is an effecter for TNF, and it is thought that inflammatory cytokines increase inducible NO synthase in brain endothelium resulting in increased NO production. $\mathrm{NO}$ is permeable to $\mathrm{BBB}$, diffusing into brain tissue, and consequently impairing neurotransmission and may be an explanation for reversible comas (Clark, Rockett et al. 1992). These toxic molecules might contribute to the pathogenesis of severe and cerebral malaria (Clark, Hunt et al. 1986; Clark, Rockett et al. 1991). However, recent clinical and experimental studies in CM have failed to support this belief (Lopansri, Anstey et al. 2003; Gramaglia, Sobolewski et al. 2006; Weinberg, Lopansri et al. 2008). Indeed, they did find good evidence for the protective role of NO in human CM (Lopansri, Anstey et al. 2003; Gramaglia, Sobolewski et al. 2006; Weinberg, Lopansri et al. 2008). Some investigators proposed that severe malaria is associated with reduced NO production and low blood levels of L-arginine, the substrate for NO synthase (Yeo, Rooslamiati et al. 2008). Cell-free hemoglobin produced by hemolysis in falciparum malaria quench NO, disrupt endothelial function, increase adhesion receptor expression and impair 
tissue perfusion (Yeo, Lampah et al. 2009). Adjunctive agents to improve endothelial NO bioavailability including L-arginine are being extensively tested in human patients (Yeo, Lampah et al. 2007; Yeo, Lampah et al. 2008; Yeo, Rooslamiati et al. 2008; Yeo, Lampah et al. 2009) and a safety pharmacokinetics profile has been established (Yeo, Rooslamiati et al. 2008).

\subsubsection{Coagulation and $\mathrm{CM}$}

The role of coagulation cascade in $\mathrm{CM}$ is controversial. However, most investigators propose that $P$. falciparum infection is associated with a procoagulant state (Francischetti 2008). Francischetti et al proved that the coagulation cascade played a crucial role in the pathogenetic processes leading to the cerebral complications (Francischetti 2008). Tissue factor expression in the endothelium, and the amplification of the coagulation cascade by pRBCs and platelets at sequestration sites, contribute critically in initiating and maintaining a coagulation-inflammation cycle which leads to cerebral involvement in falciparum malaria (Francischetti 2008). In addition to the typical role in the regulation of hemostasis, coagulation factors have an inflammatory role [having cross talk with inflammatory cytokines (Esmon, Taylor et al. 1991) that is important in the pathogenesis of CM (Moxon, Heyderman et al. 2009)]. This finding sheds new insight into potentially novel therapies for $\mathrm{CM}$. The possible pivotal role of platelets was reported recently from Malawian patients with cerebral malaria [(Wassmer, Taylor et al. 2008), see 4.4 Platelets]. Pantethine interrupted the early stages of the coagulation-inflammation cascade and prevented the cerebral syndrome in ECM model (Penet, Abou-Hamdan et al. 2008).

\subsection{Gene-expression profiling and CM}

cDNA microarray analysis from brain tissue performed in genetically resistant (CM-R) and susceptible (CM-S) mice identified 327 genes discriminated between infection stages, mouse strains and CM-R and CM-S phenotypes (Delahaye, Coltel et al. 2006; Delahaye, Coltel et al. 2007). Analysis of these 327 genes using expression analysis systematic explorer (EASE) software revealed that the clustered genes were biologically relevant to the defense response such as the response to malaria, inflammatory and immune response, and metabolism like oxidative phosphorylation, glycolysis/gluconeogenesis or tryptophan metabolism. The promising areas explored by this analysis shed new light on the key events that control CM pathogenesis and the development of therapeutic strategies. The host transcriptome database changed during pathogenesis of ECM in whole blood (Oakley, Anantharaman et al. 2011). They found over 300 potential biomarkers of ECM detectable in the circulating system by comparing CM-resistant BALB/c mice to those of susceptible C57BL/ 6 and CBA/Caj mice. Among these, some molecules such as complement component C1q, nonspecific cytotoxic cell receptor protein 1, and prostate stem cell antigen will probably be the main markers related to CM encephalopathy.

\subsection{Genetic polymorphisms associated with severe malaria 5.3.1 Common erythrocyte variants and severe malaria}

Epidemiological studies in humans and experimental animals have demonstrated that genetic factors are very important in the initiation, progression and development of disease severity as well as the clinical outcome of malaria. Erythrocyte polymorphisms (variants) are biologically relevant to malaria pathogenesis (Min-Oo and Gros 2005). The protective roles of erythrocyte variants are shown in Table 1. 


\begin{tabular}{|c|c|c|c|c|}
\hline Hb variant & $\begin{array}{l}\text { Type of } \\
\text { studies }\end{array}$ & Function & Mechanism & Reference \\
\hline \multirow[t]{2}{*}{$\mathrm{HbS}$} & $\begin{array}{l}\text { In vivo case } \\
\text { control }\end{array}$ & $\begin{array}{l}\text { Protection: CM, } \\
\text { severe anemia, } \\
\text { respiratory distress, } \\
\text { hyperparasitemia, } \\
\text { prostration, acidosis, } \\
\text { and hyperlactatemia }\end{array}$ & $\mathrm{N} / \mathrm{A}$ & $\begin{array}{l}\text { (May, Evans et } \\
\text { al. 2007) }\end{array}$ \\
\hline & $\begin{array}{l}\text { In vivo mouse } \\
\text { model C57 } \\
\text { BL/ } 6\end{array}$ & Protection: ECM & $\begin{array}{l}\text { HO-1 activation } \\
\text { via Nrf2, and } \\
\text { inhibition of CD8+ }\end{array}$ & $\begin{array}{l}\text { (Ferreira, } \\
\text { Marguti et al. } \\
\text { 2011) }\end{array}$ \\
\hline $\mathrm{HbC}$ & $\begin{array}{l}\text { In vivo case } \\
\text { control }\end{array}$ & $\begin{array}{l}\text { Protection: } \mathrm{CM} \text {, } \\
\text { severe anemia }\end{array}$ & & $\begin{array}{l}\text { (Mockenhaupt, } \\
\text { Ehrhardt et al. } \\
\text { 2004; May, Evans } \\
\text { et al. 2007) }\end{array}$ \\
\hline $\mathrm{HbF}$ & $\begin{array}{l}\text { In vitro } \\
\text { HMVEC cell } \\
\text { culture }\end{array}$ & Protection: malaria & $\begin{array}{l}\text { Impairs } \\
\text { cytoadherence of } \\
\text { pRBCs with EC } \\
\text { and monocytes }\end{array}$ & $\begin{array}{l}\text { (Amaratunga, } \\
\text { Lopera-Mesa et } \\
\text { al. 2011) }\end{array}$ \\
\hline \multirow[t]{2}{*}{$\begin{array}{l}\text { G6PD } \\
\text { deficiency }\end{array}$} & $\begin{array}{l}\text { In vivo case- } \\
\text { control }\end{array}$ & $\begin{array}{l}\text { Protection: severe } \\
\text { malaria }\end{array}$ & $\mathrm{N} / \mathrm{A}$ & $\begin{array}{l}\text { (Guindo, } \\
\text { Fairhurst et al. } \\
\text { 2007) } \\
\end{array}$ \\
\hline & $\begin{array}{l}\text { In vitro } \\
\text { culture of } P \\
\text { falciparum }\end{array}$ & Protection: malaria & $\begin{array}{l}\text { Inhibits parasite } \\
\text { growth under } \\
\text { oxidative stress } \\
\text { and susceptibility } \\
\text { to phagocytosis } \\
\end{array}$ & $\begin{array}{l}\text { (Roth, Raventos- } \\
\text { Suarez et al. 1983; } \\
\text { Cappadoro, } \\
\text { Giribaldi et al. } \\
\text { 1998) }\end{array}$ \\
\hline a-thalassaemia & $\begin{array}{l}\text { In vivo case- } \\
\text { control }\end{array}$ & $\begin{array}{l}\text { Reduces the risk of } \\
\text { severe malaria }\end{array}$ & $\begin{array}{l}\text { Reduces } \\
\text { multiplication of } \\
\text { parasites }\end{array}$ & $\begin{array}{l}\text { (Mockenhaupt, } \\
\text { Ehrhardt et al. } \\
\text { 2004) }\end{array}$ \\
\hline$\beta$-thalassaemia & $\begin{array}{l}\text { In vitro } \\
\text { culture of } P \\
\text { falciparum }\end{array}$ & $\begin{array}{l}\text { Reduces the risk of } \\
\text { severe malaria }\end{array}$ & $\begin{array}{l}\text { Enhances } \\
\text { susceptibility of } \\
\text { pRBCs to } \\
\text { phagocytosis }\end{array}$ & $\begin{array}{l}\text { (Ayi, Turrini et } \\
\text { al. 2004) }\end{array}$ \\
\hline (PK) deficiency & $\begin{array}{l}\text { In vivo mouse } \\
\text { model, C57BL } \\
/ 6 \mathrm{~J}, \mathrm{~A} / \mathrm{J}, \mathrm{C} 3 \mathrm{H} \\
\text { and SJL }\end{array}$ & Protection: malaria & $\begin{array}{l}\text { Enhances } \\
\text { susceptibility of } \\
\text { pRBCs to } \\
\text { phagocytosis }\end{array}$ & $\begin{array}{l}\text { (Min-Oo, Fortin } \\
\text { et al. 2003) }\end{array}$ \\
\hline
\end{tabular}

Table 1. Common erythrocyte variants and severe malaria

\subsubsection{Polymorphisms of the histocompatibility region (HLA)}

T-cell recognition of malaria epitopes on infected host cells through class I and II major histocompatibility complex (MHC) antigens is a basic feature of pre-erythrocytic immunity to P. falciparum malaria. Therefore high-resolution typing of HLA class I and II loci were performed (Hananantachai, Patarapotikul et al. 2005; Lyke, Fernandez-Vina et al. 2011) to test for associations of human leukocyte antigen (HLA) alleles with malaria severity. HLA-A and HLA-B, DRB1 were identified as potential susceptibility factors for CM, thus providing further evidence that polymorphism of MHC genes results in altered malaria susceptibility. 


\section{Diagnosis, prognosis and prediction of $\mathrm{CM}$ encephalopathy}

WHO proposed a definition of $\mathrm{CM}$ as a clinical syndrome characterized by coma (inability to localize a painful stimulus) at least $1 \mathrm{~h}$ after termination of a seizure or correction of hypoglycaemia, detection of asexual forms of $P$ falciparum malaria parasites on peripheral blood smears, and exclusion of other causes of encephalopathy (Idro, Jenkins et al. 2005; WHO, 2000). This definition lacks specificity, and individuals with other underlying causes of coma might be misdiagnosed as $\mathrm{CM}$. The presence of malarial retinopathy is therefore recommended to differentiate patients whose comas are caused by $P$. falciparum or other reasons (See 2.2 Retinal changes associated with CM). MRI may help in the early diagnosis of CM so that early treatment can begin and improve the clinical outcome (Vyas, Gupta et al. 2010; Rasalkar, Paunipagar et al. 2011). Due to unreliable local electricity production, operation of MRI was always interrupted and it might take longer for MRI to become a regular diagnostic technique for malaria in Sub-Saharan Africa where most of CM in children occur. This is the major reason why an NIH-supported project of clinical characterization of pediatric patients with CM using neurological MRI methods in Blantyre, Malâ̂i was not successful (Latourette, Siebert et al. 2010). More practically, the histidinerich protein II (HRP2)-based rapid diagnostic tests has shown high sensitivity compared to conventional microscopy in diagnosis of malaria and therefore may be a suitable screening method for malaria infection (Wilson, Adjei et al. 2008; Batwala, Magnussen et al. 2010).

Clinical scores to predict fatal outcome in severe malaria have been developed previously (Helbok, Kendjo et al. 2009). A recent study in Ghanaian patients demonstrated an association between fatal CM and increased serum and CSF levels of proinflammatory and proapoptotic factors including CXCL10, IL-1ra, sTNFR1, sTNFR2, sFas and decreased serum and CSF levels of neuroprotective angiogenic growth factors (PDGFbb) (Armah, Wilson et al. 2007). Further investigations in Indian patients confirmed findings from Ghana, indicating that CXCL10, sTNFR2 and sFas are positively correlated, VEGF is negatively correlated with mortality associated with CM (Jain, Armah et al. 2008). Most recently, a retrospective case-control study performed by Erdman et al (Erdman, Dhabangi et al. 2011) indicated that host soluble triggering receptor expressed on myeloid cells-1(TREM-1) and soluble FMS-like tyrosine kinase-1 (Flt-1) as the biomarkers of pediatric severe and fatal malaria. In addition, simple biomarker combinations, such as Ang-2+procalcitonin (PCT)+sICAM-1, Ang-2+CXCL10+PCT, and PCT+CXCL10+sTREM could accurately predict death in an African pediatric population. These results suggest the utility of combinatorial biomarker strategies as prognostics methods to assess malaria severity (Erdman, Dhabangi et al. 2011).

\section{New therapies for CM}

\subsection{New treatment or management of cerebral malaria}

Because of its effectiveness and cost, chloroquine has been the best and widely used antimalaria drug. Unfortunately $P$. falciparum parasite resistance to chloroquine has been observed in most of malaria-endemic areas (Chinappi, Via et al. 2010). The current recommended new therapies for $\mathrm{CM}$ are described in Table 2. These studies on new drugs against CM encephalopathy target not only parasites but the secondary damage induced by parasitemia. 


\begin{tabular}{|c|c|c|c|}
\hline $\begin{array}{l}\text { Type of } \\
\text { compound }\end{array}$ & Type of studies & Biological effects reported & Reference \\
\hline \multicolumn{4}{|c|}{ 1. Anti-plasmodial drugs } \\
\hline Artemisinin & $\begin{array}{l}\text { ICR or C57BL/ } 6 \text { mice In vivo } \\
\text { infected by } \\
\text { Plasmodium berghei } \\
\text { ANKA }(\mathrm{PbA}) \text {. }\end{array}$ & $\begin{array}{l}\text { Anti-plasmodial activity; } \\
\text { disruption of CD4+ and CD8+ T } \\
\text { cell inflammatory responses, and } \\
\text { VEGF action }\end{array}$ & $\begin{array}{l}\text { (Waknine- } \\
\text { Grinberg, } \\
\text { Hunt et al. } \\
\text { 2010) }\end{array}$ \\
\hline Curcumin & $\begin{array}{l}\text { ICR or C57BL/ } 6 \text { mice In vivo } \\
\text { infected by PbA. }\end{array}$ & $\begin{array}{l}\text { Anti-inflammatory properties and } \\
\text { anti-plasmodial activity; inhibition } \\
\text { of activity of NF- } \mathrm{k} \text {, production of } \\
\text { NO and iNOS expression }\end{array}$ & $\begin{array}{l}\text { (Waknine- } \\
\text { Grinberg, } \\
\text { McQuillan } \\
\text { et al. 2010) }\end{array}$ \\
\hline \multicolumn{4}{|c|}{ 2. Immunomodulator therapies } \\
\hline \multirow[t]{3}{*}{$\begin{array}{l}\text { Fasudil (HA- } \\
\text { 1077) }\end{array}$} & $\begin{array}{l}\text { Primary human lung In vitro } \\
\text { endothelial cells } \\
\text { (HLECs) infected } \\
\text { with P.falciparum }\end{array}$ & $\begin{array}{l}\text { A Rho kinase inhibitor, decreases } \\
\text { both NF-kappaB activation and } \\
\text { endothelial cell apoptosis }\end{array}$ & $\begin{array}{l}\text { (Taoufiq, } \\
\text { Gay et al. } \\
2008)\end{array}$ \\
\hline & $\begin{array}{l}\text { Children infected } \\
\text { with P.falciparum }\end{array}$ & Prevents endothelium apoptosis & $\begin{array}{l}\text { (Zang- } \\
\text { Edou, } \\
\text { Bisvigou } \\
\text { et al. 2010), }\end{array}$ \\
\hline & $\begin{array}{l}\text { ICR or C57BL/6 mice In vivo } \\
\text { infected with } \mathrm{PbA} \\
\text { (both mouse strains } \\
\text { serve as murine } \\
\text { models for } \mathrm{CM} \text { ) }\end{array}$ & $\begin{array}{l}\text { Does not reduce parasitemia, but } \\
\text { increases survival, delays or } \\
\text { prevents the development of } \mathrm{CM}\end{array}$ & $\begin{array}{l}\text { (Waknine- } \\
\text { Grinberg, } \\
\text { McQuillan } \\
\text { et al. 2010) }\end{array}$ \\
\hline \multirow[t]{2}{*}{$\bar{E} 6446$} & $\begin{array}{l}\text { Human PBMCs and In vitro } \\
\text { BALB/c mouse } \\
\text { spleen cells }\end{array}$ & $\begin{array}{l}\text { A synthetic antagonist of nucleic } \\
\text { acid-sensing TLRs,Low doses of } \\
\text { E6446 specifically inhibits the } \\
\text { activation of human and mouse } \\
\text { TLR9, high doses inhibits the } \\
\text { human TLR8 response to single- } \\
\text { stranded RNA }\end{array}$ & $\begin{array}{l}\text { (Franklin, } \\
\text { Ishizaka et } \\
\text { al. 2011) }\end{array}$ \\
\hline & $\begin{array}{l}\text { C57 BL/6 mice } \\
\text { infected with } \\
\text { P.berghei iRBCs }\end{array}$ & $\begin{array}{l}\text { Reduces the activation of TLR9 } \\
\text { and modulates cytokine response } \\
\text { during acute Plasmodium } \\
\text { infection, prevents limb paralysis, } \\
\text { cerebral vascular leak, and death, }\end{array}$ & $\begin{array}{l}\text { (Franklin, } \\
\text { Ishizaka et } \\
\text { al. 2011) }\end{array}$ \\
\hline \multirow[t]{2}{*}{ rHuEpo } & African children & Prevents brain damage & $\begin{array}{l}\text { (Casals- } \\
\text { Pascual, } \\
\text { Idro et al. } \\
\text { 2008) }\end{array}$ \\
\hline & $\begin{array}{l}\text { C57 BL6 and CBA/J In vitro } \\
\text { mice infected with } \\
\mathrm{PbA}\end{array}$ & $\begin{array}{l}\text { Epo decreases inflammatory } \\
\text { response and neuronal apoptosis } \\
\text { in the brain, increases survival, } \\
\text { shortens coma recovery times }\end{array}$ & $\begin{array}{l}\text { (Kaiser, } \\
\text { Texier et } \\
\text { al. 2006; } \\
\text { Bienvenu, } \\
\text { Ferrandiz } \\
\text { et al. 2008; } \\
\text { Wiese, } \\
\text { Hempel et } \\
\text { al. 2008) }\end{array}$ \\
\hline
\end{tabular}




\begin{tabular}{|c|c|c|c|c|}
\hline Hydroxyurea & $\begin{array}{l}\text { HLECs infected by } \\
\text { the P.falciparum 3D7 } \\
\text { clone in vitro }\end{array}$ & In vitro & $\begin{array}{l}\text { Up regulates ICAM-1 and } \\
\text { enhances cytoadherence, but does } \\
\text { not induce endothelial cell } \\
\text { apoptosis. In contrast, it inhibits } \\
\text { parasite growth and prevents } \\
\text { mice from developing } \\
\text { neurological syndrome }\end{array}$ & $\begin{array}{l}\text { (Pino, } \\
\text { Taoufiq et } \\
\text { al. 2006) }\end{array}$ \\
\hline \multirow[t]{2}{*}{$\begin{array}{r}\text { Statins Simva } \\
\text { statin }\end{array}$} & $\begin{array}{l}\text { C57 BL6 and CBA/J } \\
\text { mice infected with } \\
\mathrm{PbA}\end{array}$ & In vivo & $\begin{array}{l}\text { Failes to extend survival or } \\
\text { reduce parasitemia in C57BL/ } 6 \\
\text { mice infected with } \mathrm{PbA} \text {. }\end{array}$ & $\begin{array}{l}\text { (Helmers, } \\
\text { Gowda et } \\
\text { al. 2009) }\end{array}$ \\
\hline & $\begin{array}{l}\mathrm{EAE} \text { in } \mathrm{C} 57 \mathrm{BL} / 6 \\
\text { mice }\end{array}$ & In vitro & $\begin{array}{l}\text { Simvastatin potentiates } \\
\text { production of TNF and IL-6 in } \\
\text { vitro murine peritoneal } \\
\text { macrophages treated with PfGPI }\end{array}$ & $\begin{array}{l}\text { (Helmers, } \\
\text { Gowda et } \\
\text { al. 2009) }\end{array}$ \\
\hline$\overline{\mathrm{AVA}}$ & $\begin{array}{l}\text { P. falciparum cultures } \\
\text { treated by AVA }\end{array}$ & In vitro & $\begin{array}{l}\text { Atrovastatin (AVA) reduces the } \\
\text { growth of P.falciparum in vitro }\end{array}$ & $\begin{array}{l}\text { (Parquet, } \\
\text { Briolant et } \\
\text { al. 2009) }\end{array}$ \\
\hline Pantethine & $\begin{array}{l}\text { C57 BL6 and CBA/J } \\
\text { mice infected with } \\
\mathrm{PbA}\end{array}$ & In vivo & $\begin{array}{l}\text { Reduces the platelet response to } \\
\text { activation by thrombin and } \\
\text { collagen, microparticle release by } \\
\text { TNF-activated endothelial cells } \\
\text { and protects against the cerebral } \\
\text { syndrome }\end{array}$ & $\begin{array}{l}\text { (Penet, } \\
\text { Abou- } \\
\text { Hamdan } \\
\text { et al. 2008) }\end{array}$ \\
\hline LMP-420 & HBVEC & In vitro & $\begin{array}{l}\text { Inhibits endothelial cell } \\
\text { activation, i.e., the up regulation } \\
\text { of ICAM-1 and VCAM-1 on } \\
\text { HBEC, abolishes the } \\
\text { cytoadherence of ICAM-1-specific } \\
\text { P. falciparum-parasitized RBCs on } \\
\text { ECs, causes a dramatic reduction } \\
\text { of HBEC microparticle release } \\
\text { induced by TNF or LT } \\
\text { stimulation }\end{array}$ & $\begin{array}{l}\text { (Wassmer, } \\
\text { Cianciolo } \\
\text { et al. 2005) }\end{array}$ \\
\hline $\begin{array}{l}\mathrm{N} \text { - } \\
\text { acetylcysteine } \\
\text { amid (AD4) }\end{array}$ & Case control & In vivo & $\begin{array}{l}\text { Has no effect on outcomes such as } \\
\text { mortality, lactate clearance or } \\
\text { coma recovery times }\end{array}$ & $\begin{array}{l}\text { (Agbenye } \\
\text { ga, } \\
\text { Planche et } \\
\text { al. 2003; } \\
\text { Charunwa } \\
\text { tthana, } \\
\text { Abul Faiz } \\
\text { et al. 2009) }\end{array}$ \\
\hline Levamisole & Case control & In vivo & $\begin{array}{l}\text { Decreases sequestration of pRBCs } \\
\text { via inhibition of binding of } \\
\text { pRBCs to CD36 }\end{array}$ & $\begin{array}{l}\text { (Dondorp, } \\
\text { Silamut et } \\
\text { al. 2007) }\end{array}$ \\
\hline
\end{tabular}

Table 2. New treatment or management of cerebral malaria 


\subsection{Malaria vaccines and CM encephalopathy}

Malaria vaccine is urgently needed to sustain the gains of malaria control. A clinical trial ( ClinicalTrials.gov number, NCT00380393.) on 894 children conducted in Kenya and Tanzania (Bejon, Cook et al. 2011) demonstrated that RTS,S/AS01E is a very promising malaria vaccine. RTS,S is a circumspozoite protein [CSP repeat region (R)] that targets the pre-erythrocytic cycle of $P$. falciparum in humans (Lusingu, Olotu et al. 2010; Bejon, Cook et al. 2011; Olotu, Lusingu et al. 2011)]. RTS,S-containing vaccines induce pre-erythrocytic immunity, differing from naturally acquired immunity, which largely targets blood-stage parasites (Bejon, Cook et al. 2011; Olotu, Lusingu et al. 2011). RTS,S/AS01E vaccines decrease the concentrations of antibodies to merozoite antigens, which probably reflects reduced exposure to blood-stage infections. Long-term protective efficacy of RTS,S vaccination is more likely to have a direct effect of the pre erythrocytic immunity induced by the vaccine, rather than the result of enhanced acquisition of immunity to blood-stage antigens (Bejon, Cook et al. 2011; Olotu, Lusingu et al. 2011). Although these antibodies were not correlated to clinical immunity, the overall effect of RTS,S vaccines still had a significantly lower incidence of clinical malaria than did unvaccinated individuals. Protection was sustained for at least 15 months (Bejon, Cook et al. 2011). Whole-parasite vaccine strategies (Coban, Igari et al. 2010; Coban, Yagi et al. 2010; Taylor-Robinson 2010) for malaria infection have attracted researchers' attention. They trigger parasite antigen-specific immune responses through TLR9 and NOD-like receptors (NLRs) (Coban, Igari et al. 2010; Coban, Yagi et al. 2010). Heme-detoxification byproduct, hemozoin, is also being considered as a potential vaccine adjuvant against malaria (Coban, Igari et al. 2010; Coban, Yagi et al. 2010).

\section{Conclusions}

A severe complication of Plasmodium infection is cerebral malaria, a condition mainly attributed to sequestration of pRBCs, leukocytes and platelets in cerebral microcirculation and overwhelming inflammatory immune reactions of the host. CM presents as a diffuse encephalopathy caused by P. falciparum and remains a major cause of death and disability. Much effort is still needed to understand the pathophysiology of this disease at the cellular and molecular level, to enable the development of more effective therapies aimed at both eliminating parasites as well as the secondary effects they cause.

\section{Acknowledgements}

This work was supported by the National Institutes of Health grant numbers NIH-FIC (1T90-HG004151-01) for postdoctoral training in Genomics and Hemoglobinopathies, NIH/FIC/NINDS R21 and NIH-RCMI (RR033062).

\section{References}

(WHO, 2000). "Severe falciparum malaria. World Health Organization, Communicable Diseases Cluster." Trans R Soc Trop Med Hyg 94 Suppl 1(1): S1-90. 
Agbenyega, T., T. Planche, et al. (2003). "Population kinetics, efficacy, and safety of dichloroacetate for lactic acidosis due to severe malaria in children." J Clin Pharmacol 43(4): 386-396.

Aloisi, F., G. Borsellino, et al. (1995). "Cytokine regulation of astrocyte function: in-vitro studies using cells from the human brain." Int J Dev Neurosci 13(3-4): 265-274.

Amaratunga, C., T. M. Lopera-Mesa, et al. (2011). "A role for fetal hemoglobin and maternal immune IgG in infant resistance to Plasmodium falciparum malaria." PLoS One 6(4): e14798.

Anstey, N. M., J. B. Weinberg, et al. (1996). "Nitric oxide in Tanzanian children with malaria: inverse relationship between malaria severity and nitric oxide production/nitric oxide synthase type 2 expression." J Exp Med 184(2): 557-567.

Arcasoy, M. O. (2008). "The non-haematopoietic biological effects of erythropoietin." Br J Haematol 141(1): 14-31.

Armah, H. B., N. O. Wilson, et al. (2007). "Cerebrospinal fluid and serum biomarkers of cerebral malaria mortality in Ghanaian children." Malar J 6(147): 147.

Ayi, K., F. Turrini, et al. (2004). "Enhanced phagocytosis of ring-parasitized mutant erythrocytes: a common mechanism that may explain protection against falciparum malaria in sickle trait and beta-thalassemia trait." Blood 104(10): 3364-3371.

Azevedo, L. C., M. A. Pedro, et al. (2007). "Circulating microparticles as therapeutic targets in cardiovascular diseases." Recent Pat Cardiovasc Drug Discov 2(1): 41-51.

Balachandar, S. and A. Katyal (2010). "Peroxisome proliferator activating receptor (PPAR) in cerebral malaria (CM): a novel target for an additional therapy." Eur J Clin Microbiol Infect Dis.

Barry, O. P. and G. A. FitzGerald (1999). "Mechanisms of cellular activation by platelet microparticles." Thromb Haemost 82(2): 794-800.

Batwala, V., P. Magnussen, et al. (2010). "Are rapid diagnostic tests more accurate in diagnosis of plasmodium falciparum malaria compared to microscopy at rural health centres?" Malar J 9(349): 349.

Bauer, P. R., H. C. Van Der Heyde, et al. (2002). "Regulation of endothelial cell adhesion molecule expression in an experimental model of cerebral malaria." Microcirculation 9(6): 463-470.

Beare, N. A., S. Lewallen, et al. (2011). "Redefining cerebral malaria by including malaria retinopathy." Future Microbiol 6(3): 349-355.

Bejon, P., J. Cook, et al. (2011). "Effect of the Pre-erythrocytic Candidate Malaria Vaccine RTS,S/AS01E on Blood Stage Immunity in Young Children." J Infect Dis 204(1): 918.

Belcher, J. D., H. Mahaseth, et al. (2006). "Heme oxygenase-1 is a modulator of inflammation and vaso-occlusion in transgenic sickle mice." J Clin Invest 116(3): 808-816.

Belcher, J. D., J. V. Vineyard, et al. (2010). "Heme oxygenase-1 gene delivery by Sleeping Beauty inhibits vascular stasis in a murine model of sickle cell disease." J Mol Med 88(7): 665-675.

Belnoue, E., M. Kayibanda, et al. (2002). "On the pathogenic role of brain-sequestered alphabeta CD8+ T cells in experimental cerebral malaria." J Immunol 169(11): 63696375 . 
Belnoue, E., S. M. Potter, et al. (2008). "Control of pathogenic CD8+ T cell migration to the brain by IFN-gamma during experimental cerebral malaria." Parasite Immunol 30(10): 544-553.

Benveniste, E. N. (1992). "Inflammatory cytokines within the central nervous system: sources, function, and mechanism of action." Am J Physiol 263(1 Pt 1): C1-16.

Bernaudin, M., A. S. Nedelec, et al. (2002). "Normobaric hypoxia induces tolerance to focal permanent cerebral ischemia in association with an increased expression of hypoxia-inducible factor- 1 and its target genes, erythropoietin and VEGF, in the adult mouse brain." J Cereb Blood Flow Metab 22(4): 393-403.

Bienvenu, A. L., J. Ferrandiz, et al. (2008). "Artesunate-erythropoietin combination for murine cerebral malaria treatment." Acta Trop 106(2): 104-108.

Birbeck, G. L., M. E. Molyneux, et al. (2010). "Blantyre Malaria Project Epilepsy Study (BMPES) of neurological outcomes in retinopathy-positive paediatric cerebral malaria survivors: a prospective cohort study." Lancet Neurol 9(12): 1173-1181.

Biswas, A. K., A. Hafiz, et al. (2007). "Plasmodium falciparum uses gC1qR/HABP1/p32 as a receptor to bind to vascular endothelium and for platelet-mediated clumping." PLoS Pathog 3(9): 1271-1280.

Boivin, M. J., P. Bangirana, et al. (2007). "Cognitive impairment after cerebral malaria in children: a prospective study." Pediatrics 119(2): e360-366.

Brines, M. and A. Cerami (2005). "Emerging biological roles for erythropoietin in the nervous system." Nat Rev Neurosci 6(6): 484-494.

Brines, M., G. Grasso, et al. (2004). "Erythropoietin mediates tissue protection through an erythropoietin and common beta-subunit heteroreceptor." Proc Natl Acad Sci U S A 101(41): 14907-14912.

Brines, M., N. S. Patel, et al. (2008). "Nonerythropoietic, tissue-protective peptides derived from the tertiary structure of erythropoietin." Proc Natl Acad Sci U S A 105(31): 10925-10930.

Bussolati, B. and J. C. Mason (2006). "Dual role of VEGF-induced heme-oxygenase-1 in angiogenesis." Antioxid Redox Signal 8(7-8): 1153-1163.

Campanella, G. S., A. M. Tager, et al. (2008). "Chemokine receptor CXCR3 and its ligands CXCL9 and CXCL10 are required for the development of murine cerebral malaria." Proc Natl Acad Sci U S A 105(12): 4814-4819.

Campos, F. M., B. S. Franklin, et al. (2010). "Augmented plasma microparticles during acute Plasmodium vivax infection." Malar J 9(327): 327.

Cappadoro, M., G. Giribaldi, et al. (1998). "Early phagocytosis of glucose-6-phosphate dehydrogenase (G6PD)-deficient erythrocytes parasitized by Plasmodium falciparum may explain malaria protection in G6PD deficiency." Blood 92(7): 25272534.

Carter, J. A., J. A. Lees, et al. (2006). "Severe falciparum malaria and acquired childhood language disorder." Dev Med Child Neurol 48(1): 51-57.

Carter, J. A., V. Mung'ala-Odera, et al. (2005). "Persistent neurocognitive impairments associated with severe falciparum malaria in Kenyan children." J Neurol Neurosurg Psychiatry 76(4): 476-481.

Casals-Pascual, C., R. Idro, et al. (2008). "High levels of erythropoietin are associated with protection against neurological sequelae in African children with cerebral malaria." Proc Natl Acad Sci U S A 105(7): 2634-2639. 
Casals-Pascual, C., R. Idro, et al. (2009). "Can erythropoietin be used to prevent brain damage in cerebral malaria?" Trends Parasitol 25(1): 30-36.

Chaisavaneeyakorn, S., J. M. Moore, et al. (2002). "Immunity to placental malaria. III. Impairment of interleukin(IL)-12, not IL-18, and interferon-inducible protein-10 responses in the placental intervillous blood of human immunodeficiency virus/malaria-coinfected women." J Infect Dis 185(1): 127-131.

Chaiyaroj, S. C., A. S. Rutta, et al. (2004). "Reduced levels of transforming growth factorbeta1, interleukin-12 and increased migration inhibitory factor are associated with severe malaria." Acta Trop 89(3): 319-327.

Charunwatthana, P., M. Abul Faiz, et al. (2009). "N-acetylcysteine as adjunctive treatment in severe malaria: a randomized, double-blinded placebo-controlled clinical trial." Crit Care Med 37(2): 516-522.

Chen, L. and F. Sendo (2001). "Cytokine and chemokine mRNA expression in neutrophils from CBA/NSlc mice infected with Plasmodium berghei ANKA that induces experimental cerebral malaria." Parasitol Int 50(2): 139-143.

Chilongola, J., S. Balthazary, et al. (2009). "CD36 deficiency protects against malarial anaemia in children by reducing Plasmodium falciparum-infected red blood cell adherence to vascular endothelium." Trop Med Int Health 14(7): 810-816.

Chinappi, M., A. Via, et al. (2010). "On the mechanism of chloroquine resistance in Plasmodium falciparum." PLoS One 5(11): e14064.

Clark, I. A., N. H. Hunt, et al. (1986). "Oxygen-derived free radicals in the pathogenesis of parasitic disease." Adv Parasitol 25: 1-44.

Clark, I. A., K. A. Rockett, et al. (1991). "Proposed link between cytokines, nitric oxide and human cerebral malaria." Parasitol Today 7(8): 205-207.

Clark, I. A., K. A. Rockett, et al. (1992). "Possible central role of nitric oxide in conditions clinically similar to cerebral malaria." Lancet 340(8824): 894-896.

Clarke, S. E., M. C. Jukes, et al. (2008). "Effect of intermittent preventive treatment of malaria on health and education in schoolchildren: a cluster-randomised, double-blind, placebo-controlled trial." Lancet 372(9633): 127-138.

Coban, C., Y. Igari, et al. (2010). "Immunogenicity of whole-parasite vaccines against Plasmodium falciparum involves malarial hemozoin and host TLR9." Cell Host Microbe 7(1): 50-61.

Coban, C., K. J. Ishii, et al. (2007). "Pathological role of Toll-like receptor signaling in cerebral malaria." Int Immunol 19(1): 67-79.

Coban, C., M. Yagi, et al. (2010). "The malarial metabolite hemozoin and its potential use as a vaccine adjuvant." Allergol Int 59(2): 115-124.

Collins, T., M. A. Read, et al. (1995). "Transcriptional regulation of endothelial cell adhesion molecules: NF-kappa B and cytokine-inducible enhancers." Faseb J 9(10): 899-909.

Combes, V., N. Coltel, et al. (2005). "ABCA1 gene deletion protects against cerebral malaria: potential pathogenic role of microparticles in neuropathology." Am J Pathol 166(1): 295-302.

Combes, V., F. El-Assaad, et al. "Microvesiculation and cell interactions at the brainendothelial interface in cerebral malaria pathogenesis." Prog Neurobiol 91(2): 140151. 
Combes, V., F. El-Assaad, et al. (2010). "Microvesiculation and cell interactions at the brainendothelial interface in cerebral malaria pathogenesis." Prog Neurobiol 91(2): 140 151.

Combes, V., A. C. Simon, et al. (1999). "In vitro generation of endothelial microparticles and possible prothrombotic activity in patients with lupus anticoagulant." J Clin Invest 104(1): 93-102.

Combes, V., T. E. Taylor, et al. (2004). "Circulating endothelial microparticles in malawian children with severe falciparum malaria complicated with coma." Jama 291(21): 2542-2544.

Conroy, A. L., E. I. Lafferty, et al. (2009). "Whole blood angiopoietin-1 and -2 levels discriminate cerebral and severe (non-cerebral) malaria from uncomplicated malaria." Malar J 8(1): 295.

Coppinger, J. A., G. Cagney, et al. (2004). "Characterization of the proteins released from activated platelets leads to localization of novel platelet proteins in human atherosclerotic lesions." Blood 103(6): 2096-2104.

Core, A., C. Hempel, et al. (2011). "Plasmodium berghei ANKA: erythropoietin activates neural stem cells in an experimental cerebral malaria model." Exp Parasitol 127(2): 500-505.

Couper, K. N., T. Barnes, et al. (2010). "Parasite-derived plasma microparticles contribute significantly to malaria infection-induced inflammation through potent macrophage stimulation." PLoS Pathog 6(1): e1000744.

Cox, D. and S. McConkey (2010). "The role of platelets in the pathogenesis of cerebral malaria." Cell Mol Life Sci 67(4): 557-568.

Craig, A. and A. Scherf (2001). "Molecules on the surface of the Plasmodium falciparum infected erythrocyte and their role in malaria pathogenesis and immune evasion." Mol Biochem Parasitol 115(2): 129-143.

Cramer, J. P., A. K. Nussler, et al. (2005). "Age-dependent effect of plasma nitric oxide on parasite density in Ghanaian children with severe malaria." Trop Med Int Health 10(7): 672-680.

Crawley, J., S. Smith, et al. (1996). "Seizures and status epilepticus in childhood cerebral malaria." Qjm 89(8): 591-597.

D'Ombrain, M. C., T. S. Voss, et al. (2007). "Plasmodium falciparum erythrocyte membrane protein-1 specifically suppresses early production of host interferon-gamma." Cell Host Microbe 2(2): 130-138.

Datta, D., P. Banerjee, et al. (2010). "CXCR3-B can mediate growth-inhibitory signals in human renal cancer cells by downregulating the expression of heme oxygenase-1." J Biol Chem.

Datta, D., O. Dormond, et al. (2007). "Heme oxygenase-1 modulates the expression of the anti-angiogenic chemokine CXCL-10 in renal tubular epithelial cells." Am J Physiol Renal Physiol 293(4): F1222-1230.

Deininger, M. H., P. G. Kremsner, et al. (2002). "Macrophages/microglial cells in patients with cerebral malaria." Eur Cytokine Netw 13(2): 173-185.

Delahaye, N. F., N. Coltel, et al. (2007). "Gene expression analysis reveals early changes in several molecular pathways in cerebral malaria-susceptible mice versus cerebral malaria-resistant mice." BMC Genomics 8(452): 452. 
Delahaye, N. F., N. Coltel, et al. (2006). "Gene-expression profiling discriminates between cerebral malaria (CM)-susceptible mice and CM-resistant mice." J Infect Dis 193(2): 312-321.

Di Perri, G., I. G. Di Perri, et al. (1995). "Pentoxifylline as a supportive agent in the treatment of cerebral malaria in children." J Infect Dis 171(5): 1317-1322.

Doeuvre, L., L. Plawinski, et al. (2009). "Cell-derived microparticles: a new challenge in neuroscience." J Neurochem 110(2): 457-468.

Dondorp, A. M., K. Silamut, et al. (2007). "Levamisole inhibits sequestration of infected red blood cells in patients with falciparum malaria." J Infect Dis 196(3): 460-466.

Dong, Y. and E. N. Benveniste (2001). "Immune function of astrocytes." Glia 36(2): 180-190.

Dugbartey, A. T., F. J. Spellacy, et al. (1998). "Somatosensory discrimination deficits following pediatric cerebral malaria." Am J Trop Med Hyg 59(3): 393-396.

Eddleston, M. and L. Mucke (1993). "Molecular profile of reactive astrocytes--implications for their role in neurologic disease." Neuroscience 54(1): 15-36.

Ehrich, J. H. and F. U. Eke (2007). "Malaria-induced renal damage: facts and myths." Pediatr Nephrol 22(5): 626-637.

El Kasmi, K. C., J. Holst, et al. (2006). "General nature of the STAT3-activated antiinflammatory response." J Immunol 177(11): 7880-7888.

Epiphanio, S., M. G. Campos, et al. "VEGF promotes malaria-associated acute lung injury in mice." PLoS Pathog 6(5): e1000916.

Erdman, L. K., G. Cosio, et al. (2009). "CD36 and TLR interactions in inflammation and phagocytosis: implications for malaria." J Immunol 183(10): 6452-6459.

Erdman, L. K., A. Dhabangi, et al. (2011). "Combinations of host biomarkers predict mortality among Ugandan children with severe malaria: a retrospective casecontrol study." PLoS One 6(2): e17440.

Esmon, C. T., F. B. Taylor, Jr., et al. (1991). "Inflammation and coagulation: linked processes potentially regulated through a common pathway mediated by protein C." Thromb Haemost 66(1): 160-165.

Faille, D., V. Combes, et al. (2009). "Platelet microparticles: a new player in malaria parasite cytoadherence to human brain endothelium." Faseb J 23(10): 3449-3458.

Ferrara, N. (2004). "Vascular endothelial growth factor: basic science and clinical progress." Endocr Rev 25(4): 581-611.

Ferreira, A., I. Marguti, et al. (2011). "Sickle hemoglobin confers tolerance to Plasmodium infection." Cell 145(3): 398-409.

Francischetti, I. M. (2008). "Does activation of the blood coagulation cascade have a role in malaria pathogenesis?" Trends Parasitol 24(6): 258-263.

Franklin, B. S., S. T. Ishizaka, et al. (2011). "Therapeutical targeting of nucleic acid-sensing Toll-like receptors prevents experimental cerebral malaria." Proc Natl Acad Sci U S A 108(9): 3689-3694.

Frei, K., U. V. Malipiero, et al. (1989). "On the cellular source and function of interleukin 6 produced in the central nervous system in viral diseases." Eur J Immunol 19(4): 689694.

Frei, K., C. Siepl, et al. (1987). "Antigen presentation and tumor cytotoxicity by interferongamma-treated microglial cells." Eur J Immunol 17(9): 1271-1278. 
Geuken, E., C. I. Buis, et al. (2005). "Expression of heme oxygenase-1 in human livers before transplantation correlates with graft injury and function after transplantation." Am J Transplant 5(8): 1875-1885.

Ghezzi, P. and M. Brines (2004). "Erythropoietin as an antiapoptotic, tissue-protective cytokine." Cell Death Differ 11 Suppl 1(1): S37-44.

Gillrie, M. R., G. Krishnegowda, et al. (2007). "Src-family kinase dependent disruption of endothelial barrier function by Plasmodium falciparum merozoite proteins." Blood 110(9): 3426-3435.

Giulian, D., T. J. Baker, et al. (1986). "Interleukin 1 of the central nervous system is produced by ameboid microglia." J Exp Med 164(2): 594-604.

Giulian, D. and L. B. Lachman (1985). "Interleukin-1 stimulation of astroglial proliferation after brain injury." Science 228(4698): 497-499.

Giulian, D., D. G. Young, et al. (1988). "Interleukin-1 is an astroglial growth factor in the developing brain." J Neurosci 8(2): 709-714.

Gramaglia, I., P. Sobolewski, et al. (2006). "Low nitric oxide bioavailability contributes to the genesis of experimental cerebral malaria." Nat Med 12(12): 1417-1422.

Grau, G. E., L. F. Fajardo, et al. (1987). "Tumor necrosis factor (cachectin) as an essential mediator in murine cerebral malaria." Science 237(4819): 1210-1212.

Guindo, A., R. M. Fairhurst, et al. (2007). "X-linked G6PD deficiency protects hemizygous males but not heterozygous females against severe malaria." PLoS Med 4(3): e66.

Gyan, B., B. Q. Goka, et al. (2009). "Cerebral malaria is associated with low levels of circulating endothelial progenitor cells in African children." Am J Trop Med Hyg 80(4): 541-546.

Hananantachai, H., J. Patarapotikul, et al. (2005). "Polymorphisms of the HLA-B and HLADRB1 genes in Thai malaria patients." Jpn J Infect Dis 58(1): 25-28.

Hansen, D. S., N. J. Bernard, et al. (2007). "NK cells stimulate recruitment of CXCR3+ T cells to the brain during Plasmodium berghei-mediated cerebral malaria." J Immunol 178(9): 5779-5788.

Hansen, D. S., M. A. Siomos, et al. (2003). "Regulation of murine cerebral malaria pathogenesis by CD1d-restricted NKT cells and the natural killer complex." Immunity 18(3): 391-402.

Hanum, P. S., M. Hayano, et al. (2003). "Cytokine and chemokine responses in a cerebral malaria-susceptible or -resistant strain of mice to Plasmodium berghei ANKA infection: early chemokine expression in the brain." Int Immunol 15(5): 633-640.

Haque, A., S. E. Best, et al. (2011). "High parasite burdens cause liver damage in mice following Plasmodium berghei ANKA infection independently of CD8(+) T cellmediated immune pathology." Infect Immun 79(5): 1882-1888.

Haque, A., S. E. Best, et al. (2010). "CD4+ natural regulatory T cells prevent experimental cerebral malaria via CTLA-4 when expanded in vivo." PLoS Pathog 6(12): e1001221.

Haque, A., S. E. Best, et al. (2011). "Granzyme B Expression by CD8+ T Cells Is Required for the Development of Experimental Cerebral Malaria." J Immunol 186(11): 6148-6156.

Hasselblatt, M., H. Ehrenreich, et al. (2006). "The brain erythropoietin system and its potential for therapeutic exploitation in brain disease." J Neurosurg Anesthesiol 18(2): 132-138. 
Helbok, R., E. Kendjo, et al. (2009). "The Lambarene Organ Dysfunction Score (LODS) is a simple clinical predictor of fatal malaria in African children." J Infect Dis 200(12): 1834-1841.

Helmers, A. J., D. C. Gowda, et al. (2009). "Statins fail to improve outcome in experimental cerebral malaria and potentiate Toll-like receptor-mediated cytokine production by murine macrophages." Am J Trop Med Hyg 81(4): 631-637.

Hemmer, C. J., H. A. Lehr, et al. (2005). "Plasmodium falciparum Malaria: reduction of endothelial cell apoptosis in vitro." Infect Immun 73(3): 1764-1770.

Hermsen, C., T. van de Wiel, et al. (1997). "Depletion of CD4+ or CD8+ T-cells prevents Plasmodium berghei induced cerebral malaria in end-stage disease." Parasitology 114 ( Pt 1)(Pt 1): 7-12.

Ho, M., M. J. Hickey, et al. (2000). "Visualization of Plasmodium falciparum-endothelium interactions in human microvasculature: mimicry of leukocyte recruitment." J Exp Med 192(8): 1205-1211.

Holding, P. A., J. Stevenson, et al. (1999). "Cognitive sequelae of severe malaria with impaired consciousness." Trans R Soc Trop Med Hyg 93(5): 529-534.

Hunt, N. H., J. Golenser, et al. (2006). "Immunopathogenesis of cerebral malaria." Int J Parasitol 36(5): 569-582.

Hunt, N. H. and G. E. Grau (2003). "Cytokines: accelerators and brakes in the pathogenesis of cerebral malaria." Trends Immunol 24(9): 491-499.

Hunt, N. H. and R. Stocker (2007). "Heme moves to center stage in cerebral malaria." Nat Med 13(6): 667-669.

Idro, R., N. E. Jenkins, et al. (2005). "Pathogenesis, clinical features, and neurological outcome of cerebral malaria." Lancet Neurol 4(12): 827-840.

Idro, R., K. Marsh, et al. (2010). "Cerebral malaria: mechanisms of brain injury and strategies for improved neurocognitive outcome." Pediatr Res 68(4): 267-274.

Ikenoue, N., S. Kawazu, et al. (2002). "PCR-amplification, sequencing, and comparison of the var/PfEMP-1 gene from the blood of patients with falciparum malaria in the Philippines." Southeast Asian J Trop Med Public Health 33 Suppl 3: 8-13.

Jain, V., H. B. Armah, et al. (2008). "Plasma IP-10, apoptotic and angiogenic factors associated with fatal cerebral malaria in India." Malar J 7(83): 83.

Jain, V., P. P. Singh, et al. (2009). "A preliminary study on pro- and anti-inflammatory cytokine profiles in Plasmodium vivax malaria patients from central zone of India." Acta Trop 113(3): 263-268.

John, C. C., P. Bangirana, et al. (2008). "Cerebral malaria in children is associated with longterm cognitive impairment." Pediatrics 122(1): e92-99.

John, C. C., R. Opika-Opoka, et al. (2006). "Low levels of RANTES are associated with mortality in children with cerebral malaria." J Infect Dis 194(6): 837-845.

John, C. C., A. Panoskaltsis-Mortari, et al. (2008). "Cerebrospinal fluid cytokine levels and cognitive impairment in cerebral malaria." Am J Trop Med Hyg 78(2): 198-205.

John, C. C., G. S. Park, et al. (2008). "Elevated serum levels of IL-1ra in children with Plasmodium falciparum malaria are associated with increased severity of disease." Cytokine 41(3): 204-208.

Kaiser, K., A. Texier, et al. (2006). "Recombinant human erythropoietin prevents the death of mice during cerebral malaria." J Infect Dis 193(7): 987-995. 
Kang, S. S. and D. B. McGavern (2010). "Microbial induction of vascular pathology in the CNS." J Neuroimmune Pharmacol 5(3): 370-386.

Kim, H. P., X. Wang, et al. (2004). "Caveolae compartmentalization of heme oxygenase-1 in endothelial cells." FASEB J 18(10): 1080-1089.

Labbe, K., J. Miu, et al. (2010). "Caspase-12 dampens the immune response to malaria independently of the inflammasome by targeting NF-kappaB signaling." J Immunol 185(9): 5495-5502.

Lackner, P., C. Burger, et al. (2007). "Apoptosis in experimental cerebral malaria: spatial profile of cleaved caspase-3 and ultrastructural alterations in different disease stages." Neuropathol Appl Neurobiol 33(5): 560-571.

Latourette, M. T., J. E. Siebert, et al. (2010). "Magnetic Resonance Imaging Research in SubSaharan Africa: Challenges and Satellite-Based Networking Implementation." J Digit Imaging 17: 17.

Lin, Q., S. Weis, et al. (2007). "Heme oxygenase-1 protein localizes to the nucleus and activates transcription factors important in oxidative stress." J Biol Chem 282(28): 20621-20633.

Liu, M., S. Guo, et al. (2011). "CXCL10/IP-10 in infectious diseases pathogenesis and potential therapeutic implications." Cytokine Growth Factor Rev 27: 27.

Lobov, I. B., P. C. Brooks, et al. (2002). "Angiopoietin-2 displays VEGF-dependent modulation of capillary structure and endothelial cell survival in vivo." Proc Natl Acad Sci U S A 99(17): 11205-11210.

Looareesuwan, S., P. Wilairatana, et al. (1998). "Pentoxifylline as an ancillary treatment for severe falciparum malaria in Thailand." Am J Trop Med Hyg 58(3): 348-353.

Lopansri, B. K., N. M. Anstey, et al. (2003). "Low plasma arginine concentrations in children with cerebral malaria and decreased nitric oxide production." Lancet 361(9358): 676-678.

Lucas, R., J. N. Lou, et al. (1997). "Respective role of TNF receptors in the development of experimental cerebral malaria." J Neuroimmunol 72(2): 143-148.

Lusingu, J., A. Olotu, et al. (2010). "Safety of the malaria vaccine candidate, RTS,S/AS01E in 5 to 17 month old Kenyan and Tanzanian Children." PLoS One 5(11): e14090.

Lyke, K. E., M. A. Fernandez-Vina, et al. (2011). "Association of HLA alleles with Plasmodium falciparum severity in Malian children." Tissue Antigens 77(6): 562571.

Lynch, S. F. and C. A. Ludlam (2007). "Plasma microparticles and vascular disorders." Br J Haematol 137(1): 36-48.

Maiese, K., F. Li, et al. (2005). "New avenues of exploration for erythropoietin." Jama 293(1): 90-95.

Marsh, K., M. English, et al. (1996). "The pathogenesis of severe malaria in African children." Ann Trop Med Parasitol 90(4): 395-402.

Masuda, S., M. Nagao, et al. (1993). "Functional erythropoietin receptor of the cells with neural characteristics. Comparison with receptor properties of erythroid cells." J Biol Chem 268(15): 11208-11216.

Masuda, S., M. Okano, et al. (1994). "A novel site of erythropoietin production. Oxygendependent production in cultured rat astrocytes." J Biol Chem 269(30): 19488-19493.

May, J., J. A. Evans, et al. (2007). "Hemoglobin variants and disease manifestations in severe falciparum malaria." Jama 297(20): 2220-2226. 
McEver, R. P. (2001). "Adhesive interactions of leukocytes, platelets, and the vessel wall during hemostasis and inflammation." Thromb Haemost 86(3): 746-756.

McQuillan, J. A., A. J. Mitchell, et al. (2011). "Coincident parasite and CD8 T cell sequestration is required for development of experimental cerebral malaria." Int J Parasitol 41(2): 155-163.

Medana, I. M., T. Chan-Ling, et al. (1996). "Redistribution and degeneration of retinal astrocytes in experimental murine cerebral malaria: relationship to disruption of the blood-retinal barrier." Glia 16(1): 51-64.

Medana, I. M., T. Chan-Ling, et al. (2000). "Reactive changes of retinal microglia during fatal murine cerebral malaria: effects of dexamethasone and experimental permeabilization of the blood-brain barrier." Am J Pathol 156(3): 1055-1065.

Medana, I. M., G. Chaudhri, et al. (2001). "Central nervous system in cerebral malaria: 'Innocent bystander' or active participant in the induction of immunopathology?" Immunol Cell Biol 79(2): 101-120.

Medana, I. M., N. P. Day, et al. (2002). "Axonal injury in cerebral malaria." Am J Pathol 160(2): 655-666.

Medana, I. M., N. P. Day, et al. (2003). "Metabolites of the kynurenine pathway of tryptophan metabolism in the cerebrospinal fluid of Malawian children with malaria." J Infect Dis 188(6): 844-849.

Medana, I. M., T. T. Hien, et al. (2002). "The clinical significance of cerebrospinal fluid levels of kynurenine pathway metabolites and lactate in severe malaria." J Infect Dis 185(5): 650-656.

Medana, I. M., N. H. Hunt, et al. (1997). "Early activation of microglia in the pathogenesis of fatal murine cerebral malaria." Glia 19(2): 91-103.

Medana, I. M., N. H. Hunt, et al. (1997). "Tumor necrosis factor-alpha expression in the brain during fatal murine cerebral malaria: evidence for production by microglia and astrocytes." Am J Pathol 150(4): 1473-1486.

Medana, I. M., R. Idro, et al. (2007). "Axonal and astrocyte injury markers in the cerebrospinal fluid of Kenyan children with severe malaria." J Neurol Sci 258(1-2): 93-98.

Medana, I. M. and G. D. Turner (2006). "Human cerebral malaria and the blood-brain barrier." Int J Parasitol 36(5): 555-568.

Metenou, S., B. Dembele, et al. (2009). "Patent filarial infection modulates malaria-specific type 1 cytokine responses in an IL-10-dependent manner in a filaria/malariacoinfected population." J Immunol 183(2): 916-924.

Min-Oo, G., A. Fortin, et al. (2003). "Pyruvate kinase deficiency in mice protects against malaria." Nat Genet 35(4): 357-362.

Min-Oo, G. and P. Gros (2005). "Erythrocyte variants and the nature of their malaria protective effect." Cell Microbiol 7(6): 753-763.

Mishra, S. K. and L. Wiese (2009). "Advances in the management of cerebral malaria in adults." Curr Opin Neurol 22(3): 302-307.

Miu, J., A. J. Mitchell, et al. (2008). "Chemokine gene expression during fatal murine cerebral malaria and protection due to CXCR3 deficiency." J Immunol 180(2): 1217-1230.

Mockenhaupt, F. P., S. Ehrhardt, et al. (2004). "Hemoglobin C and resistance to severe malaria in Ghanaian children." J Infect Dis 190(5): 1006-1009. 
Mockenhaupt, F. P., S. Ehrhardt, et al. (2004). "Alpha(+)-thalassemia protects African children from severe malaria." Blood 104(7): 2003-2006.

Moxon, C. A., R. S. Heyderman, et al. (2009). "Dysregulation of coagulation in cerebral malaria." Mol Biochem Parasitol 166(2): 99-108.

Mucke, L. and M. Eddleston (1993). "Astrocytes in infectious and immune-mediated diseases of the central nervous system." Faseb J 7(13): 1226-1232.

Nagai, A., E. Nakagawa, et al. (2001). "Erythropoietin and erythropoietin receptors in human CNS neurons, astrocytes, microglia, and oligodendrocytes grown in culture." J Neuropathol Exp Neurol 60(4): 386-392.

Nantakomol, D., A. M. Dondorp, et al. (2011). "Circulating red cell-derived microparticles in human malaria." J Infect Dis 203(5): 700-706.

Newton, C. R., J. Crawley, et al. (1997). "Intracranial hypertension in Africans with cerebral malaria." Arch Dis Child 76(3): 219-226.

Newton, C. R., N. Peshu, et al. (1994). "Brain swelling and ischaemia in Kenyans with cerebral malaria." Arch Dis Child 70(4): 281-287.

Ngoungou, E. B. and P. M. Preux (2008). "Cerebral malaria and epilepsy." Epilepsia 49 Suppl 6: 19-24.

Nitcheu, J., O. Bonduelle, et al. (2003). "Perforin-dependent brain-infiltrating cytotoxic CD8+ $\mathrm{T}$ lymphocytes mediate experimental cerebral malaria pathogenesis." J Immunol 170(4): 2221-2228.

Nomura, S., A. Shouzu, et al. (2009). "Assessment of an ELISA kit for platelet-derived microparticles by joint research at many institutes in Japan." J Atheroscler Thromb 16(6): 878-887.

Oakley, M. S., V. Anantharaman, et al. (2011). "Molecular correlates of experimental cerebral malaria detectable in whole blood." Infect Immun 79(3): 1244-1253.

Ochola, L. B., B. R. Siddondo, et al. (2011). "Specific receptor usage in Plasmodium falciparum cytoadherence is associated with disease outcome." PLoS One 6(3): e14741.

Olotu, A., J. Lusingu, et al. (2011). "Efficacy of RTS,S/AS01E malaria vaccine and exploratory analysis on anti-circumsporozoite antibody titres and protection in children aged 5-17 months in Kenya and Tanzania: a randomised controlled trial." Lancet Infect Dis 11(2): 102-109.

Omer, F. M. and E. M. Riley (1998). "Transforming growth factor beta production is inversely correlated with severity of murine malaria infection." J Exp Med 188(1): 39-48.

Opoka, R. O., P. Bangirana, et al. (2009). "Seizure activity and neurological sequelae in Ugandan children who have survived an episode of cerebral malaria." Afr Health Sci 9(2): 75-81.

Pae, H. O., G. S. Oh, et al. (2005). "A molecular cascade showing nitric oxide-heme oxygenase-1-vascular endothelial growth factor-interleukin-8 sequence in human endothelial cells." Endocrinology 146(5): 2229-2238.

Pain, A., D. J. Ferguson, et al. (2001). "Platelet-mediated clumping of Plasmodium falciparum-infected erythrocytes is a common adhesive phenotype and is associated with severe malaria." Proc Natl Acad Sci U S A 98(4): 1805-1810.

Pamplona, A., A. Ferreira, et al. (2007). "Heme oxygenase-1 and carbon monoxide suppress the pathogenesis of experimental cerebral malaria." Nat Med 13(6): 703-710. 
Pamplona, A., T. Hanscheid, et al. (2009). "Cerebral malaria and the hemolysis/methemoglobin/heme hypothesis: shedding new light on an old disease." Int J Biochem Cell Biol 41(4): 711-716.

Pankoui Mfonkeu, J. B., I. Gouado, et al. (2010). "Elevated cell-specific microparticles are a biological marker for cerebral dysfunctions in human severe malaria." PLoS One 5(10): e13415.

Parquet, V., S. Briolant, et al. (2009). "Atorvastatin is a promising partner for antimalarial drugs in treatment of Plasmodium falciparum malaria." Antimicrob Agents Chemother 53(6): 2248-2252.

Patankar, T. F., D. R. Karnad, et al. (2002). "Adult cerebral malaria: prognostic importance of imaging findings and correlation with postmortem findings." Radiology 224(3): 811-816.

Penet, M. F., M. Abou-Hamdan, et al. (2008). "Protection against cerebral malaria by the lowmolecular-weight thiol pantethine." Proc Natl Acad Sci U S A 105(4): 1321-1326.

Penet, M. F., A. Viola, et al. (2005). "Imaging experimental cerebral malaria in vivo: significant role of ischemic brain edema." J Neurosci 25(32): 7352-7358.

Picot, S., A. L. Bienvenu, et al. (2009). "Safety of epoietin beta-quinine drug combination in children with cerebral malaria in Mali." Malar J 8(169): 169.

Pino, P., Z. Taoufiq, et al. (2006). "Effects of hydroxyurea on malaria, parasite growth and adhesion in experimental models." Parasite Immunol 28(12): 675-680.

Pino, P., I. Vouldoukis, et al. (2003). "Plasmodium falciparum--infected erythrocyte adhesion induces caspase activation and apoptosis in human endothelial cells." J Infect Dis 187(8): 1283-1290.

Polack, B., F. Delolme, et al. (1997). "Protective role of platelets in chronic (Balb/C) and acute (CBA/J) Plasmodium berghei murine malaria." Haemostasis 27(6): 278-285.

Potchen, M. J., G. L. Birbeck, et al. (2010). "Neuroimaging findings in children with retinopathy-confirmed cerebral malaria." Eur J Radiol 74(1): 262-268.

Potter, S. M., T. Chan-Ling, et al. (2006). "A role for Fas-Fas ligand interactions during the late-stage neuropathological processes of experimental cerebral malaria." J Neuroimmunol 173(1-2): 96-107.

Rasalkar, D. D., B. K. Paunipagar, et al. (2011). "Magnetic resonance imaging in cerebral malaria: a report of four cases." Br J Radiol 84(1000): 380-385.

Reis, P. A., C. M. Comim, et al. (2010). "Cognitive dysfunction is sustained after rescue therapy in experimental cerebral malaria, and is reduced by additive antioxidant therapy." PLoS Pathog 6(6): e1000963.

Rogerson, S. J., G. E. Grau, et al. (2004). "The microcirculation in severe malaria." Microcirculation 11(7): 559-576.

Romagnani, S. (1997). "The Th1/Th2 paradigm." Immunol Today 18(6): 263-266.

Roos, M. A., L. Gennero, et al. (2010). "Microparticles in physiological and in pathological conditions." Cell Biochem Funct 28(7): 539-548.

Roth, E. F., Jr., C. Raventos-Suarez, et al. (1983). "Glucose-6-phosphate dehydrogenase deficiency inhibits in vitro growth of Plasmodium falciparum." Proc Natl Acad Sci U S A 80(1): 298-299.

Ryter, S. W. and A. M. Choi (2009). "Heme oxygenase-1/carbon monoxide: from metabolism to molecular therapy." Am J Respir Cell Mol Biol 41(3): 251-260. 
Sargin, D., A. El-Kordi, et al. (2011). "Expression of constitutively active erythropoietin receptor in pyramidal neurons of cortex and hippocampus boosts higher cognitive functions in mice." BMC Biol 9(27): 27.

Schofield, L. and F. Hackett (1993). "Signal transduction in host cells by a glycosylphosphatidylinositol toxin of malaria parasites." J Exp Med 177(1): 145-153.

Schofield, L., S. Novakovic, et al. (1996). "Glycosylphosphatidylinositol toxin of Plasmodium up-regulates intercellular adhesion molecule-1, vascular cell adhesion molecule-1, and E-selectin expression in vascular endothelial cells and increases leukocyte and parasite cytoadherence via tyrosine kinase-dependent signal transduction." J Immunol 156(5): 1886-1896.

Schroit, A. J., J. W. Madsen, et al. (1985). "In vivo recognition and clearance of red blood cells containing phosphatidylserine in their plasma membranes." J Biol Chem 260(8): 5131-5138.

Seixas, E., J. F. Moura Nunes, et al. (2009). "The interaction between DC and Plasmodium berghei/chabaudi-infected erythrocytes in mice involves direct cell-to-cell contact, internalization and TLR." Eur J Immunol 39(7): 1850-1863.

Serghides, L. and K. C. Kain (2001). "Peroxisome proliferator-activated receptor gammaretinoid $\mathrm{X}$ receptor agonists increase CD36-dependent phagocytosis of Plasmodium falciparum-parasitized erythrocytes and decrease malaria-induced TNF-alpha secretion by monocytes/macrophages." J Immunol 166(11): 6742-6748.

Sharma, Y. D. (1997). "Knob proteins in falciparum malaria." Indian J Med Res 106: 53-62.

Shi, X., L. Qin, et al. (2008). "Dynamic balance of pSTAT1 and pSTAT3 in C57BL/6 mice infected with lethal or nonlethal Plasmodium yoelii." Cell Mol Immunol 5(5): 341348.

Shirafuji, T., H. Hamaguchi, et al. (2008). "Measurement of platelet-derived microparticle levels in the chronic phase of cerebral infarction using an enzyme-linked immunosorbent assay." Kobe J Med Sci 54(1): E55-61.

Silamut, K., N. H. Phu, et al. (1999). "A quantitative analysis of the microvascular sequestration of malaria parasites in the human brain." Am J Pathol 155(2): 395-410.

Sims, P. J., E. M. Faioni, et al. (1988). "Complement proteins C5b-9 cause release of membrane vesicles from the platelet surface that are enriched in the membrane receptor for coagulation factor $\mathrm{Va}$ and express prothrombinase activity." J Biol Chem 263(34): 18205-18212.

Siren, A. L., T. Fasshauer, et al. (2009). "Therapeutic potential of erythropoietin and its structural or functional variants in the nervous system." Neurotherapeutics 6(1): 108-127.

Straus, D. S., G. Pascual, et al. (2000). "15-deoxy-delta 12,14-prostaglandin J2 inhibits multiple steps in the NF-kappa B signaling pathway." Proc Natl Acad Sci U S A 97(9): 4844-4849.

Sun, G., W. L. Chang, et al. (2003). "Inhibition of platelet adherence to brain microvasculature protects against severe Plasmodium berghei malaria." Infect Immun 71(11): 6553-6561.

Szklarczyk, A., M. Stins, et al. (2007). "Glial activation and matrix metalloproteinase release in cerebral malaria." J Neurovirol 13(1): 2-10. 
Tada, M., A. C. Diserens, et al. (1994). "Analysis of cytokine receptor messenger RNA expression in human glioblastoma cells and normal astrocytes by reversetranscription polymerase chain reaction." J Neurosurg 80(6): 1063-1073.

Takeda, M., M. Kikuchi, et al. (2005). "Microsatellite polymorphism in the heme oxygenase-1 gene promoter is associated with susceptibility to cerebral malaria in Myanmar." Jpn J Infect Dis 58(5): 268-271.

Taoufiq, Z., F. Gay, et al. (2008). "Rho kinase inhibition in severe malaria: thwarting parasiteinduced collateral damage to endothelia." J Infect Dis 197(7): 1062-1073.

Taylor-Robinson, A. W. (2010). "Regulation of immunity to Plasmodium: implications from mouse models for blood stage malaria vaccine design." Exp Parasitol 126(3): 406414.

Taylor, T. E., W. J. Fu, et al. (2004). "Differentiating the pathologies of cerebral malaria by postmortem parasite counts." Nat Med 10(2): 143-145.

Togbe, D., P. L. de Sousa, et al. (2008). "Both functional LTbeta receptor and TNF receptor 2 are required for the development of experimental cerebral malaria." PLoS One 3(7): e2608.

Treutiger, C. J., A. Heddini, et al. (1997). "PECAM-1/CD31, an endothelial receptor for binding Plasmodium falciparum-infected erythrocytes." Nat Med 3(12): 1405-1408.

Tripathi, A. K., W. Sha, et al. (2009). "Plasmodium falciparum-infected erythrocytes induce NF-kappaB regulated inflammatory pathways in human cerebral endothelium." Blood 114(19): 4243-4252.

Tripathi, A. K., D. J. Sullivan, et al. (2006). "Plasmodium falciparum-infected erythrocytes increase intercellular adhesion molecule 1 expression on brain endothelium through NF-kappaB." Infect Immun 74(6): 3262-3270.

Ullal, A. J., D. S. Pisetsky, et al. (2010). "Use of SYTO 13, a fluorescent dye binding nucleic acids, for the detection of microparticles in in vitro systems." Cytometry A 77(3): 294-301.

Van den Steen, P. E., K. Deroost, et al. (2008). "CXCR3 determines strain susceptibility to murine cerebral malaria by mediating $\mathrm{T}$ lymphocyte migration toward IFNgamma-induced chemokines." Eur J Immunol 38(4): 1082-1095.

van der Heyde, H. C., I. Gramaglia, et al. (2005). "Platelet depletion by anti-CD41 (alphaIIb) $\mathrm{mAb}$ injection early but not late in the course of disease protects against Plasmodium berghei pathogenesis by altering the levels of pathogenic cytokines." Blood 105(5): 1956-1963.

Veerasubramanian, P., P. Gosi, et al. (2006). "Artesunate and a major metabolite, dihydroartemisinin, diminish mitogen-induced lymphocyte proliferation and activation." Southeast Asian J Trop Med Public Health 37(5): 838-847.

Vyas, S., V. Gupta, et al. (2010). "Magnetic Resonance Imaging of Cerebral Malaria." J Emerg Med 11: 11.

Waknine-Grinberg, J. H., N. Hunt, et al. (2010). "Artemisone effective against murine cerebral malaria." Malar J 9(227): 227.

Waknine-Grinberg, J. H., J. A. McQuillan, et al. (2010). "Modulation of cerebral malaria by fasudil and other immune-modifying compounds." Exp Parasitol 125(2): 141-146.

Walker, O., L. A. Salako, et al. (1992). "Prognostic risk factors and post mortem findings in cerebral malaria in children." Trans R Soc Trop Med Hyg 86(5): 491-493. 
Wang, J. X., W. Tang, et al. (2007). "Investigation of the immunosuppressive activity of artemether on T-cell activation and proliferation." Br J Pharmacol 150(5): 652-661.

Wang, Z., J. Qiu, et al. (2007). "Anti-inflammatory properties and regulatory mechanism of a novel derivative of artemisinin in experimental autoimmune encephalomyelitis." J Immunol 179(9): 5958-5965.

Wassmer, S. C., G. J. Cianciolo, et al. (2005). "Inhibition of endothelial activation: a new way to treat cerebral malaria?" PLoS Med 2(9): e245.

Wassmer, S. C., V. Combes, et al. (2006). "Platelets potentiate brain endothelial alterations induced by Plasmodium falciparum." Infect Immun 74(1): 645-653.

Wassmer, S. C., V. Combes, et al. (2003). "Pathophysiology of cerebral malaria: role of host cells in the modulation of cytoadhesion." Ann N Y Acad Sci 992: 30-38.

Wassmer, S. C., J. B. de Souza, et al. (2006). "TGF-beta1 released from activated platelets can induce TNF-stimulated human brain endothelium apoptosis: a new mechanism for microvascular lesion during cerebral malaria." J Immunol 176(2): 1180-1184.

Wassmer, S. C., T. Taylor, et al. (2008). "Platelet-induced clumping of Plasmodium falciparum-infected erythrocytes from Malawian patients with cerebral malariapossible modulation in vivo by thrombocytopenia." J Infect Dis 197(1): 72-78.

Weinberg, J. B., B. K. Lopansri, et al. (2008). "Arginine, nitric oxide, carbon monoxide, and endothelial function in severe malaria." Curr Opin Infect Dis 21(5): 468-475.

Wenisch, C., S. Looareesuwan, et al. (1998). "Effect of pentoxifylline on cytokine patterns in the therapy of complicated Plasmodium falciparum malaria." Am J Trop Med Hyg 58(3): 343-347.

White, V. A. (2011). "Malaria in Malawi: inside a research autopsy study of pediatric cerebral malaria." Arch Pathol Lab Med 135(2): 220-226.

White, V. A., S. Lewallen, et al. (2009). "Retinal pathology of pediatric cerebral malaria in Malawi." PLoS One 4(1): e4317.

Wiese, L., C. Hempel, et al. (2008). "Recombinant human erythropoietin increases survival and reduces neuronal apoptosis in a murine model of cerebral malaria." Malar J $7(3): 3$.

Wilson, N. O., A. A. Adjei, et al. (2008). "Detection of Plasmodium falciparum histidine-rich protein II in saliva of malaria patients." Am J Trop Med Hyg 78(5): 733-735.

Wilson, N. O., T. Bythwood, et al. (2010). "Elevated levels of IL-10 and G-CSF associated with asymptomatic malaria in pregnant women." Infect Dis Obstet Gynecol 2010: 12.

Wilson, N. O., M. B. Huang, et al. (2008). "Soluble factors from Plasmodium falciparuminfected erythrocytes induce apoptosis in human brain vascular endothelial and neuroglia cells." Mol Biochem Parasitol 162(2): 172-176.

Wilson, N. O., V. Jain, et al. (2011). "CXCL4 and CXCL10 predict risk of fatal cerebral malaria." Dis Markers 30(1): 39-49.

$\mathrm{Xu}, \mathrm{H} .$, Y. He, et al. (2007). "Anti-malarial agent artesunate inhibits TNF-alpha-induced production of proinflammatory cytokines via inhibition of NF-kappaB and PI3 kinase/Akt signal pathway in human rheumatoid arthritis fibroblast-like synoviocytes." Rheumatology (Oxford) 46(6): 920-926.

Yanez, D. M., J. Batchelder, et al. (1999). "Gamma delta T-cell function in pathogenesis of cerebral malaria in mice infected with Plasmodium berghei ANKA." Infect Immun 67(1): 446-448. 
Yanez, D. M., D. D. Manning, et al. (1996). "Participation of lymphocyte subpopulations in the pathogenesis of experimental murine cerebral malaria." J Immunol 157(4): 16201624.

Yeo, T. W., D. A. Lampah, et al. (2007). "Impaired nitric oxide bioavailability and L-arginine reversible endothelial dysfunction in adults with falciparum malaria." J Exp Med 204(11): 2693-2704.

Yeo, T. W., D. A. Lampah, et al. (2008). "Recovery of endothelial function in severe falciparum malaria: relationship with improvement in plasma L-arginine and blood lactate concentrations." J Infect Dis 198(4): 602-608.

Yeo, T. W., D. A. Lampah, et al. (2009). "Relationship of cell-free hemoglobin to impaired endothelial nitric oxide bioavailability and perfusion in severe falciparum malaria." J Infect Dis 200(10): 1522-1529.

Yeo, T. W., I. Rooslamiati, et al. (2008). "Pharmacokinetics of L-arginine in adults with moderately severe malaria." Antimicrob Agents Chemother 52(12): 4381-4387.

Yipp, B. G., M. J. Hickey, et al. (2007). "Differential roles of CD36, ICAM-1, and P-selectin in Plasmodium falciparum cytoadherence in vivo." Microcirculation 14(6): 593-602.

Yipp, B. G., S. M. Robbins, et al. (2003). "Src-family kinase signaling modulates the adhesion of Plasmodium falciparum on human microvascular endothelium under flow." Blood 101(7): 2850-2857.

$\mathrm{Yu}, \mathrm{H}$. and R. Jove (2004). "The STATs of cancer--new molecular targets come of age." Nat Rev Cancer 4(2): 97-105.

Zang-Edou, E. S., U. Bisvigou, et al. (2010). "Inhibition of Plasmodium falciparum field isolates-mediated endothelial cell apoptosis by Fasudil: therapeutic implications for severe malaria." PLoS One 5(10): e13221.

Zhu, J., X. Wu, et al. (2009). "MAPK-activated protein kinase 2 differentially regulates plasmodium falciparum glycosylphosphatidylinositol-induced production of tumor necrosis factor-\{alpha\} and interleukin-12 in macrophages." J Biol Chem 284(23): 15750-15761. 


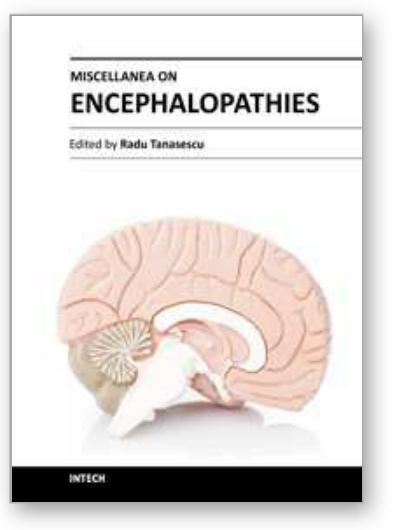

\author{
Miscellanea on Encephalopathies \\ Edited by Dr. Radu Tanasescu
}

ISBN 978-953-51-0499-5

Hard cover, 202 pages

Publisher InTech

Published online 18, April, 2012

Published in print edition April, 2012

The book project "Miscellanea on Encephalopathies" aims to cover some of the important aspects of infectious-related encephalopathies, post-transplantation and drug-induced encephalopathies, by transmitting valuable information filtered through the real life clinical and research experience of the authors.

\title{
How to reference
}

In order to correctly reference this scholarly work, feel free to copy and paste the following:

Mingli Liu, Shanchun Guo, Monica Battle and Jonathan K. Stiles (2012). Current Advances in Cerebral Malaria Associated Encephalopathy, Miscellanea on Encephalopathies, Dr. Radu Tanasescu (Ed.), ISBN: 978-953-510499-5, InTech, Available from: http://www.intechopen.com/books/miscellanea-on-encephalopathies/currentadvances-in-cerebral-malaria-associated-encephalopathy

\section{INTECH}

open science | open minds

\section{InTech Europe}

University Campus STeP Ri

Slavka Krautzeka 83/A

51000 Rijeka, Croatia

Phone: +385 (51) 770447

Fax: +385 (51) 686166

www.intechopen.com

\section{InTech China}

Unit 405, Office Block, Hotel Equatorial Shanghai

No.65, Yan An Road (West), Shanghai, 200040, China 中国上海市延安西路65号上海国际贵都大饭店办公楼 405 单元

Phone: +86-21-62489820

Fax: $+86-21-62489821$ 
(C) 2012 The Author(s). Licensee IntechOpen. This is an open access article distributed under the terms of the Creative Commons Attribution 3.0 License, which permits unrestricted use, distribution, and reproduction in any medium, provided the original work is properly cited. 